\title{
Orion Launch Abort Vehicle Attitude Control Motor Testing - Invited
}

\author{
Kelly J. Murphy*, Gregory J. Brauckmann †, Keith B. Paschal \\ David T. Chan§, Eric L. Walker*, \\ NASA Langley Research Center, Hampton, Virginia, 23681 \\ Robert Foley ${ }^{\dagger \dagger}$, David Mayfield $\$$, Jared Cross $\$ \S$ \\ Lockheed Martin Space Systems Co., Denver, CO 80201
}

Current Orion Launch Abort Vehicle (LAV) configurations use an eight-jet, solidfueled Attitude Control Motor (ACM) to provide required vehicle control for all proposed abort trajectories. Due to the forward position of the ACM on the LAV, it is necessary to assess the effects of jet-interactions (JI) between the various ACM nozzle plumes and the external flow along the outside surfaces of the vehicle. These JI-induced changes in flight control characteristics must be accounted for in developing ACM operations and LAV flight characteristics. A test program to generate jet interaction aerodynamic increment data for multiple LAV configurations was conducted in the NASA Ames and NASA Langley Unitary Plan Wind Tunnels from August 2007 through December 2009. Using cold air as the simulant gas, powered subscale models were used to generate interaction data at subsonic, transonic, and supersonic test conditions. This paper presents an overview of the complete ACM JI experimental test program for Orion LAV configurations, highlighting ACM system modeling, nozzle scaling assumptions, experimental test techniques, and data reduction methodologies. Lessons learned are discussed, and sample jet interaction data are shown. These data, in conjunction with computational predictions, were used to create the ACM JI increments for all relevant flight databases.

\section{Nomenclature}

\begin{tabular}{|c|c|c|c|}
\hline $\mathrm{A}_{\text {exit }}$ & Nozzle exit area, in ${ }^{2}$ & $\mathrm{R}$ & Gas constant, ft-lbf $/ 1 \mathrm{bm}-{ }^{\circ} \mathrm{R}$ \\
\hline $\mathrm{AF}$ & Axial force, lbs & $\mathrm{Re} / \mathrm{ft}$ & Freestream unit Reynolds number \\
\hline $\mathrm{B}_{\text {ref }}$ & Reference span, in. & $\mathrm{RM}$ & Rolling Moment, in-lbs \\
\hline $\mathrm{C}_{\mathrm{A}}$ & Axial-force coefficient & $\mathrm{SF}$ & Side force, lbs \\
\hline Cfg & Thrust loss parameter & $\mathrm{S}_{\mathrm{ref}}$ & Model reference area, $\mathrm{ft}^{2}$ \\
\hline $\mathrm{C}_{1}$ & Rolling-moment coefficient & TB & Thrust balance \\
\hline $\mathrm{C}_{\mathrm{m}}$ & Pitching-moment coefficient & $\mathrm{T}_{\mathrm{i}}$ & Individual nozzle thrust, lbs \\
\hline \multicolumn{4}{|c|}{ * Aerospace Engineer, Aerothermodynamics Branch, MS408 } \\
\hline \multicolumn{4}{|c|}{$\dagger$ Aerospace Engineer, Aerothermodynamics Branch, MS408, Associate Fellow AIAA } \\
\hline \multicolumn{4}{|c|}{$\$$ Aerospace Engineer, Flow Physics Branch, MS170 } \\
\hline \multicolumn{4}{|c|}{$\S$ Aerospace Engineer, Configuration Aerodynamics Branch, MS407, Member AIAA } \\
\hline \multicolumn{4}{|c|}{ ** Aerospace Engineer, Configuration Aerodynamics Branch, MS267, Lifetime Senior Member, AIAA } \\
\hline \multicolumn{4}{|c|}{$\dagger \dagger$ Aerospace Engineer } \\
\hline \multicolumn{4}{|c|}{$\$$ Aerospace Engineer } \\
\hline \multicolumn{4}{|c|}{$\S \S$ Aerospace Engineer } \\
\hline
\end{tabular}




$\begin{array}{llll}\mathrm{C}_{\mathrm{n}} & \text { Yawing-moment coefficient } & \mathrm{T}_{\max } & \text { Maximum nozzle thrust } \\ \mathrm{C}_{\mathrm{N}} & \text { Normal-force coefficient } & \mathrm{T}_{\mathrm{net}} & \text { Resultant thrust vector, lbs } \\ \mathrm{C}_{\mathrm{P}} & \text { Pressure coefficient } & \mathrm{TR} & \text { Thrust ratio } \\ \mathrm{C}_{\mathrm{ref}} & \text { Reference chord, in. } & \mathrm{TR}_{\mathrm{s}} & \text { System thrust ratio } \\ \mathrm{C}_{\mathrm{Y}} & \text { Side-force coefficient } & \mathrm{T}_{\mathrm{T}} & \text { Freestream total temperature, }{ }^{\circ} \mathrm{R} \\ \mathrm{D} & \text { Diameter, in. } & \mathrm{T}_{\mathrm{v}} & \text { Nozzle vacuum thrust, lbs } \\ \mathrm{F} & \text { Thrust, lbf } & \mathrm{V}_{\mathrm{exit}} & \text { Exit velocity } \\ \mathrm{F}_{\mathrm{ideal}} & \text { Ideal thrust, lbf } & \mathrm{X}_{\mathrm{mrc}} & \text { X-coordinate of MRC, in } \\ \dot{m} & \text { Mass flow, lbm/sec } & \mathrm{Y}_{\mathrm{mrc}} & \text { Y-coordinate of MRC, in. } \\ \mathrm{M}_{\mathrm{e}} & \text { nozzle exit Mach number } & \mathrm{YM} & \text { Yawing Moment, in-lbs } \\ \mathrm{M}_{\infty} & \text { freestream Mach number } & \mathrm{Z}_{\mathrm{mrc}} & \text { Z-coordinate of MRC, in. } \\ \mathrm{N}_{\mathrm{i}} & \text { ACM nozzle designation } & \alpha & \text { Angle of attack, deg. } \\ \mathrm{NF} & \text { Normal force, lbs } & \beta & \text { Angle of sideslip, deg. } \\ \mathrm{NPR} & \text { Nozzle pressure ratio } & \Delta \mathrm{Cm}{ }_{\mathrm{acm}} & \mathrm{C}_{\mathrm{m}} \text { increment due to ACM JI } \\ \mathrm{PM} & \text { Pitching moment, in-lbs } & \phi & \text { Model azimuth angle, deg. } \\ \mathrm{P}_{\mathrm{T}} & \text { Freestream total pressure, psf } & \gamma & \text { Ratio of specific heats } \\ \mathrm{q}_{\infty} & \text { Freestream dynamic pressure, psf } & \theta_{\mathrm{i}} & \text { Nozzle azimuth angle, deg. }\end{array}$

\section{Introduction}

The Apollo-derived Orion crew exploration vehicle was part of NASA's now-cancelled Constellation Program to return humans to the moon and other destinations in the solar system. Work continues on the Orion spacecraft as part of the nation's future manned

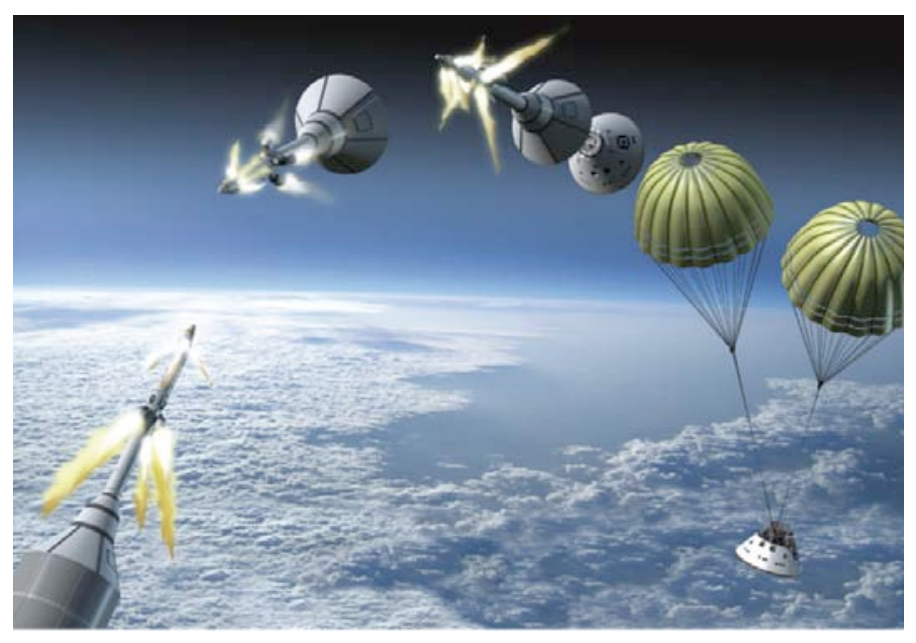

Figure 1. Orion LAV Abort Sequence space transportation system. To maximize the crew's safety, Orion includes a Launch Abort System (LAS) capable of pulling the spacecraft and its crew to safety in the event of an emergency on the launch pad or at any time during the ascent (Figure 1). The LAS-605-068 with the Orion Crew Module (CM) was the Launch Abort Vehicle (LAV) configuration successfully flown for the PadAbort 1 (PA-1) flight test in May 2010. The current LAV planned for operational use is the Alternate Launch Abort System (ALAS) configuration, with a modified adapter cone and boost protective cover (BPC), as shown in Figures 2 and 3. The BPC was re-designed from the 068 configuration in order to reduce high aeroacoustic loads at transonic and supersonic flight conditions. Figure 2 shows the LAS-605-068 with the Orion crew module. Figure 3 shows a similar figure for the LAS-606-ALAS configuration. All wind tunnel test data were acquired for these two configurations. 


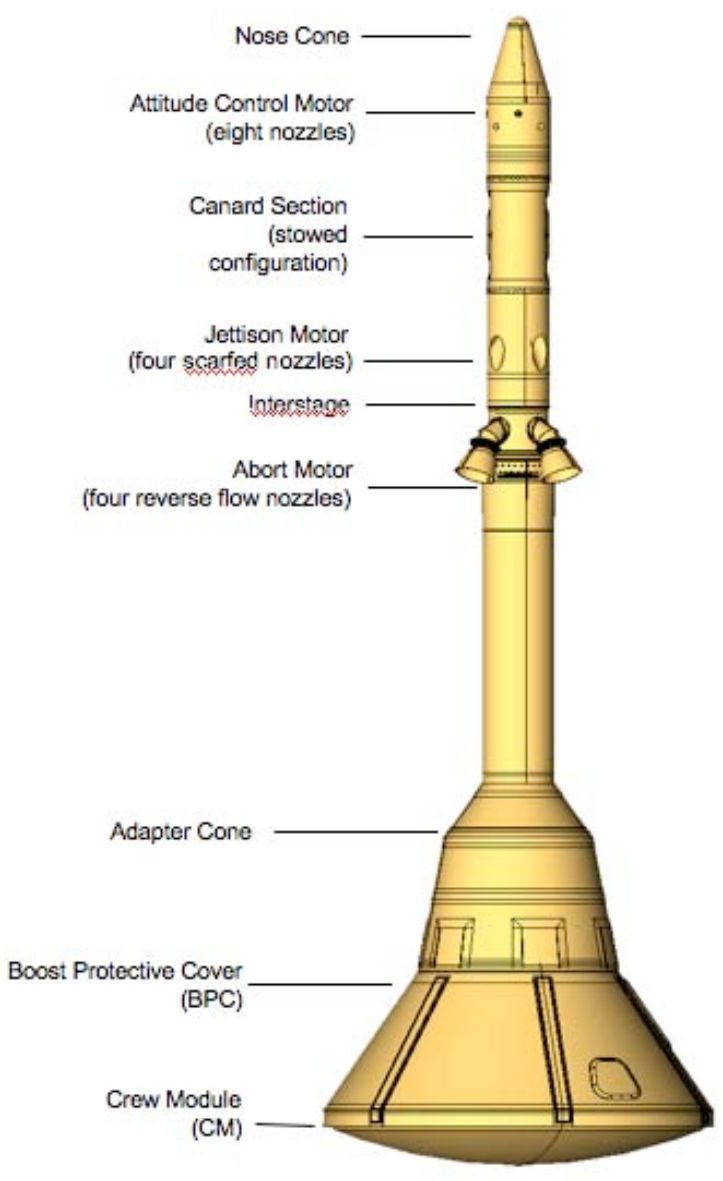

Figure 2. LAS-605-068 with the Orion crew module.

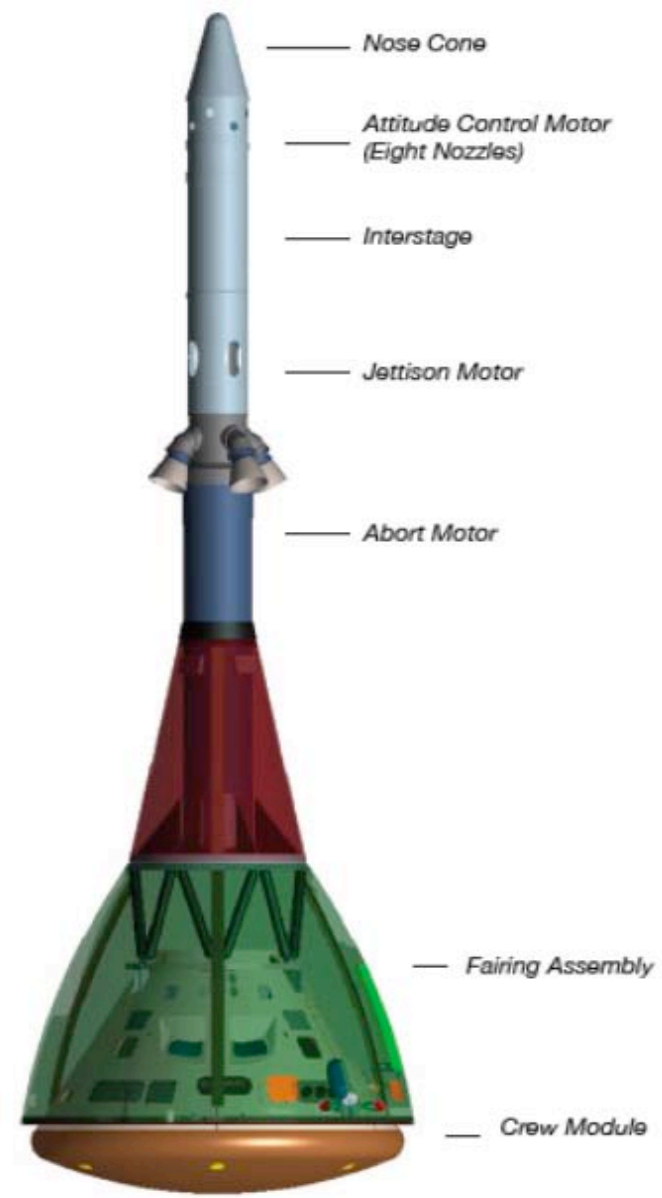

Figure 3. LAS-606-ALAS with the Orion crew module.

Both LAS designs use an Attitude Control Motor (ACM), located just aft of the LAS nose cone, to control the Launch Abort Vehicle (LAV) for all proposed abort trajectories. The ACM is a solid rocket motor fired through 8 variable-thrust, circumferential nozzles (Figure 4). The system consists of a combustion chamber with a single solid propellant grain, a common plenum that transfers the hot gases from the combustion chamber to the thrusters, and 8 nozzles with independently controlled pintles to vary the throat area and thus the thrust. The nozzles are designated N1 through N8 with N1 at an azimuth angle of $22.5^{\circ}$ from the top and the others following at $45^{\circ}$ increments (Figure 5).

Due to the forward position of the ACM on the LAV, it is necessary to assess the effects of jet-interactions (JI) between the various ACM nozzle plumes and the external flow along the outside surfaces of the vehicle. The complex JI effects are expected to result in localized aerodynamic disturbances that can yield significant and highly non-linear control amplifications, attenuations, or reversals. These changes in flight control characteristics must be accounted for in developing ACM operations and LAV flight characteristics. 


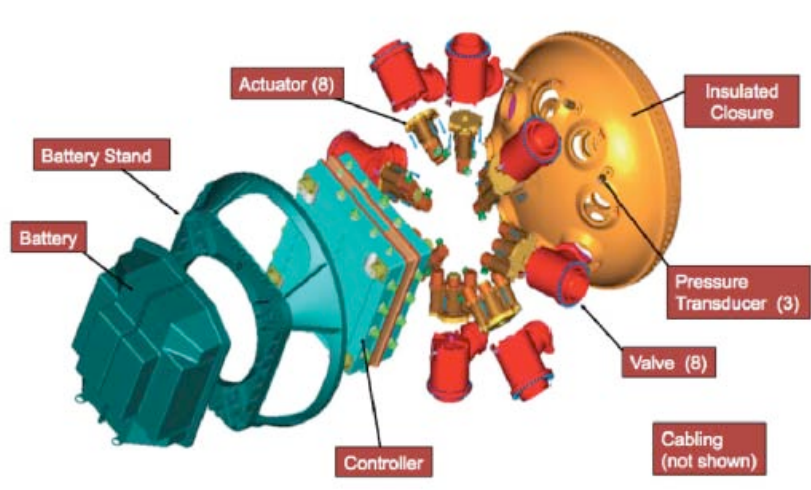

Figure 4. Schematic of the Attitude Control Motor design.

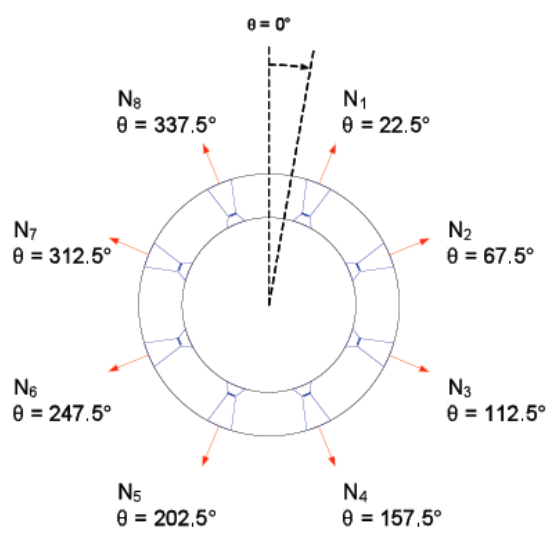

Figure 5. Schematic of ACM nozzle arrangement for Orion LAV.

\section{Objectives}

A test program to generate jet interaction aerodynamic increment data for the Orion LAV at subsonic, transonic, and supersonic test conditions was conducted in the NASA Ames and NASA Langley Unitary Plan Wind Tunnel (UPWT) Facilities from August 2007 through December 2009. The objectives of this test program were as follows:

(1) Generate benchmark ACM jet interaction data over a range of subsonic, transonic, and supersonic Mach numbers and relevant angles of attack and sideslip for the LAS-605-068 and LAS-606-ALAS (ALAS-11 Rev. 3c) configurations to populate the aerodynamic flight databases for proposed pad abort and ascent abort flight test trajectories.

(2) Use ACM experimental data to validate computational fluid dynamic (CFD) predictions of ACM JI effects.

(3) For given free stream conditions, generate ACM jet interaction data over a range of thrust levels to gain insight into sensitivity of jet-to-freestream scaling parameters.

The test program described herein includes information from CEV Aeroscience Project (CAP) Tests 59-AA, 75-AA, and 76-AA and involved personnel and resources from NASA Langley Research Center, NASA Ames Research Center, NASA Johnson Space Flight Center, Lockheed Martin Space Sciences, Orbital Sciences, Boeing, and Northrop Grumman.

CAP test reports extensively document all aspects of these three test programs and present a large volume of ACM jet interaction data generated across the speed regime. These data are currently ITAR (International Traffic in Arm Regulations) controlled, and thus data magnitudes cannot be published in open literature. Therefore this report does not seek specifically to discuss trends within the ACM data collected and its impact on 
the LAV. The purpose of the present work is to present an overview of the complete ACM JI experimental test program for Orion LAV configurations, describing ACM modeling parameters, nozzle scaling assumptions, experimental test techniques, and data reduction methodologies. Sample jet interaction data are shown with scales removed, and lessons learned are discussed.

\section{ACM Modeling}

Experimentally modeling the operation of the eight-nozzle attitude control motor design and simulating both individual and collective nozzle performance characteristics presented numerous challenges. Model and infrastructure limitations and their affects on scaling and simulation will be discussed below.

As shown in Figure 5, the ACM system operates as a collection of 8 circumferential nozzles. To populate the LAS flight database, a prioritized subset of system thrust allocations (combined thrust level and resultant thrust direction) was selected and modeled experimentally. The ACM is fueled by a solid grain propellant and thus once initiated, the system will continually generate thrust that must be managed. Maximum control authority is obtained when total thrust is maximized along the resultant thrust vector. When the vehicle requires no corrective moments in flight, the motor thrust must be balanced through the nozzles into a null configuration. Transition between the maximum and null thrust conditions encompasses the design space that must be characterized over the complete range of azimuth angles and thrust ratios for jet interactions. Vehicle trajectories and aerodynamic characteristics of the LAV dictated thrust allocation priorities.

Thrust direction is the azimuth angle, $\theta_{\mathrm{r}}$, of the resultant thrust vector. The overall vacuum thrust ratio (commonly defined as thrust coefficient in propulsion literature) from the eight nozzles is defined as:

$$
\mathrm{TR}=\frac{1}{q_{\infty} S} \sum_{i=1}^{8} T_{v, i} \cdot\left|\cos \left(\theta_{i}-\theta_{r}\right)\right|
$$

Thrust balance is defined as the ratio of thrust in the direction of the resultant thrust to the total thrust aligned along the thrust vector (thrust in either direction along the thrust vector):

$$
\mathrm{TB}=\frac{\sum_{j=1}^{8} T_{v, j} \cdot\left|\cos \left(\theta_{j}-\theta_{r}\right)\right|}{\sum_{j=1}^{8} T_{v, j} \cdot\left|\cos \left(\theta_{j}-\theta_{r}\right)\right|} \quad 0^{\circ} \leq\left|\theta_{j}-\theta_{r}\right| \leq 90^{\circ} \quad \text { or } \quad 270^{\circ} \leq\left|\theta_{j}-\theta_{r}\right| \leq 360^{\circ}
$$

Given the above definitions, the thrust balance will vary from 0.5 for a null condition to 1.0 for a maximum thrust condition. In addition, a system thrust ratio $\left(\mathrm{TR}_{\mathrm{s}}\right)$ is defined as the ratio of maximum thrust of any one nozzle to the total system thrust. Total system 
thrust is the sum of the individual nozzle thrust values:

$$
T R_{s}=\frac{T_{\max }}{\sum_{i=1}^{8} T_{v, i}}
$$

Figure 6 shows graphical representations of null, mid, and max thrust allocations at $0^{\circ}$ azimuth angle. Based on the above characterization, the ACM database requires six independent variables - thrust ratio, thrust balance, thrust direction, Mach, alpha, and beta - to uniquely define the ACM.
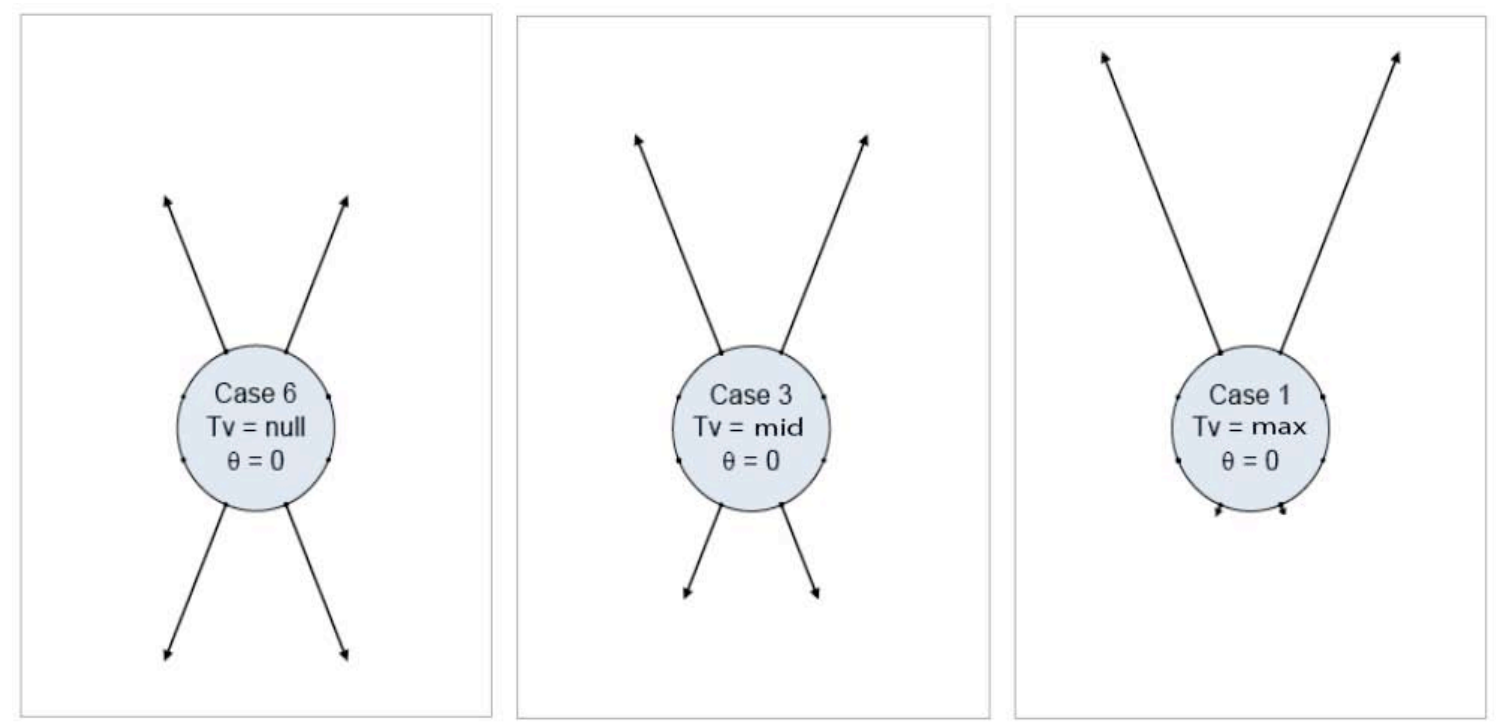

Figure 6. Schematic representation of null, mid, and maximum thrust allocations at $0^{\circ}$ azimuth angle.

Orbital Sciences Corporation (OSC), lead subcontractor for the LAS, developed the thrust allocation algorithm used to define the individual nozzle thrusts required to obtain a specified overall thrust level and direction. Predicted flight-vehicle chamber pressures and nozzle expansion ratios provided by OSC were initial inputs for modeling ACM nozzles for 5\%-scale wind tunnel models. Exit conditions, necessary to compute scaling parameters such as thrust ratio and exit pressure ratio, were calculated using the Chemical Equilibrium with Applications (CEA) computer code. ${ }^{1}$

Nozzle scaling methodologies to define nozzle geometries evolved over the course of the two-year test program. For the initial ACM test 59-AA (LAS-605-068 configuration), vacuum thrust ratio (Equation 1) and exit Mach number were selected as the scaling parameters based on review of the literature and discussions with Orion partners. For tests 75-AA and 76-AA (ALAS-11 Rev. 3c configuration), the decision was made to use vacuum thrust ratio and an average of exit Mach number and $\gamma \mathrm{M}_{\mathrm{e}}{ }^{2}$ to allow for better simulation of the exit pressure ratio and thus plume size. Nozzles were designed and fabricated to satisfy 12 different thrust allocations (summarized in a subsequent section). 
Other simulation parameters of interest were momentum flux ratio, exit pressure ratio, and mass flow ratio. There were several physical constraints that affected the ability to simultaneously match all aforementioned simulation parameters. The only available highpressure fluid source was unheated air. The exit Mach number for an individual nozzle was limited initially to $\mathrm{M}_{\mathrm{e}}=3.55$ for the first test entry, and lowered to $\mathrm{M}_{\mathrm{e}}=3.4$ for later tests, to avoid liquifaction within the nozzle. All nozzles had to be fed by a single chamber pressure with a maximum value of approximately 2800 psia. This constraint forced several nozzles to be modified (usually by lowering exit Mach number and/or reducing exit and throat areas) in order to match the overall thrust ratio. A compromise design for each allocation was achieved that minimized differences in individual exit pressure ratios and thrust ratios, and maintained relative jet strength (ratio of one jet thrust to another). Also, fabrication techniques limited nozzle throat diameters to a minimum of roughly 0.015 in. A more detailed explanation of ACM nozzle scaling methods for this test program is presented in Reference 2.

\section{Experimental Program}

\section{Facilities}

All ACM JI test data were acquired in the Ames and Langley Unitary Plan Wind Tunnels. The Ames UPWT provided subsonic, transonic and low supersonic test data $\left(\mathrm{M}_{\infty}=0.3\right.$ to $\left.\mathrm{M}_{\infty}=2.5\right)$. The Langley UPWT allowed overlap conditions at $\mathrm{M}_{\infty}=2.5$ and was used to generate high supersonic freestream conditions $\left(\mathrm{M}_{\infty}=2.5\right.$ to $\left.\mathrm{M}_{\infty}=4.5\right)$.

\section{Ames Unitary Plan Wind Tunnel}

The ARC Unitary Plan Wind Tunnel (UPWT) consists of three tunnel legs: the 11x11Foot Transonic Wind Tunnel (TWT), the 9x7-Foot Supersonic Wind Tunnel (SWT), and the $8 \times 7$ SWT (currently non-operational). All legs operate as closed-circuit, variablepressure, continuous operation wind tunnels. The 11x11-Foot TWT leg can be operated over a Mach number range of 0.2 to 1.45 , and at total pressures up to 32 psia. Operating air temperatures can range from $80^{\circ} \mathrm{F}$ to $150^{\circ} \mathrm{F}$, but standard operating temperature is approximately $100^{\circ} \mathrm{F}$. The tunnel can reach a maximum Reynolds number of $9.6 \times 10^{6} / \mathrm{ft}$ at $\mathrm{M}_{\infty}=1.2$. Over the transonic range $\left(0.7 \leq \mathrm{M}_{\infty} \leq 1.4\right)$ the tunnel can reach a Reynolds number of $8.0 \times 10^{6} / \mathrm{ft}$. The $9 \times 7$-Foot SWT can be operated over a Mach number range of 1.5 to 2.5 , and at total pressures up to 26 psia. Operating air temperatures can range from $80^{\circ} \mathrm{F}$ to $150^{\circ} \mathrm{F}$, but the facility is normally operated at temperatures around $100^{\circ} \mathrm{F}$. The maximum achievable Reynolds number is primarily limited by available compressor power of $176 \mathrm{MW}$. A Reynolds number of $5.0 \times 10^{6} / \mathrm{ft}$ can be reached over most of the tunnel's Mach range. In contrast to standard mounting in the 11x11-Foot TWT, models in the 9x7-Foot SWT are typically mounted at a 90-degree rotation to the gravity vector such that models are pitched in the tunnel yaw plane. A general description of the facility can be found at http://windtunnels.arc.nasa.gov/, with more detailed information found in Reference 3. Table 1 presents nominal operating conditions for both the $11-\mathrm{ft}$ and $9 \mathrm{x} 7 \mathrm{ft}$ test sections for Mach numbers where ACM JI data were acquired. The ARC UPWT has an independent high-pressure air delivery system that can provide installed models with compressed air at pressures up to approximately 3000 psi. A three-compressor array can 
provide mass flows up to $26 \mathrm{lbm} / \mathrm{sec}$ through dual, independently regulated lines ending within the support strut. Flow rates are controlled by means of a digital valve system and can be set in increments of 0.01 pounds per second, repeatable to 0.02 pounds per second. An outlet pressure control mode is also available with a tolerance of $\pm 2 \%$ of set point. For mass flows greater than $0.5 \mathrm{lbm} / \mathrm{sec}$, a one-megawatt, heater can preheat air from one high-pressure line, with a maximum heater outlet temperature of $400^{\circ} \mathrm{F}$.

Table 1. Nominal operating conditions for the ARC UPWT.

\begin{tabular}{|c|c|c|c|c|}
\hline Mach & $\boldsymbol{R e} / \mathbf{f t}\left(\boldsymbol{x 1 0 ^ { 6 }}\right)$ & $\boldsymbol{P}_{\boldsymbol{T}}(\boldsymbol{p s} \boldsymbol{f})$ & $\boldsymbol{T}_{\boldsymbol{T}}(\boldsymbol{d e g} \boldsymbol{R})$ & $\boldsymbol{q}(\boldsymbol{p s f})$ \\
\hline 0.3 & 3.0 & 3187 & 530 & 189 \\
\hline 0.5 & 3.0 & 2050 & 531 & 302 \\
\hline 0.7 & 3.0 & 1638 & 535 & 405 \\
\hline 0.9 & 3.0 & 1461 & 540 & 490 \\
\hline 0.95 & 3.0 & 1422 & 537 & 503 \\
\hline 1.05 & 3.0 & 1404 & 541 & 539 \\
\hline 1.1 & 3.0 & 1385 & 541 & 550 \\
\hline 1.3 & 3.0 & 1388 & 544 & 593 \\
\hline 1.6 & 3.0 & 1511 & 556 & 637 \\
\hline 2.0 & 3.0 & 1759 & 558 & 629 \\
\hline 2.5 & 3.0 & 2271 & 563 & 582 \\
\hline
\end{tabular}

LaRC Unitary Plan Wind Tunnel

The NASA Langley Research Center Unitary Plan Wind Tunnel (UPWT) is a closedcircuit continuous flow pressure tunnel with two test sections that are nominally 4-ft by 4-ft in cross section and 7 feet long. The Mach number range is approximately 1.50 to 2.86 in Test Section 1 and 2.30 to 4.63 in Test Section 2. Test Section 2 was used exclusively for this study. The stagnation pressure can be varied up to a maximum of approximately 100 psia in Test Section 2 Typical unit Reynolds numbers for testing in the UPWT Test Section 2 are 1.0 to 5.0 million per foot, but for the present study Reynolds number was limited to increase maximize obtainable thrust ratios. The tunnel stagnation temperatures are typically $125 \mathrm{deg}$. F and $150 \mathrm{deg}$. F depending on the mode of operation. Table 3.2 presents nominal operating conditions for Mach numbers where ACM JI data were acquired. The most recent calibration of the tunnel is provided by Jackson, et al., while a recent description of facility capabilities can be found in Reference 5. A new capability for supplying high-pressure air to the model was recently added to the UPWT complex. High-pressure air supplied from the Center's compressor station at nearly $5000 \mathrm{psi}$ is controlled and fed to the model through a digital control valve (DCV). The DCV provides manual control of both temperature (using an inline heater) and pressure. The system design requirements for control of temperature and pressure are ambient to $275^{\circ} \mathrm{F}$ and 50 psi to $3800 \mathrm{psi}$, respectively. The mass flow control range is 0.02 to $30 \mathrm{lbm} / \mathrm{s}$ at these conditions. Control accuracy is thought to be better than $\pm 2 \%$ for the pressure range of $50-250 \mathrm{psi}, \pm 1 \%$ for the pressure range of 250 $3800 \mathrm{psi}$, and $\pm 5^{\circ} \mathrm{F}$ in temperature. The quoted accuracy on mass flow is $\pm 0.5 \mathrm{lbm} / \mathrm{s}$. Mass flow was independently measured by an in-line Coriolis meter described in a subsequent section. 
Table 2. Nominal operating conditions for the LaRC UPWT, Test Section 2.

\begin{tabular}{|c|c|c|c|c|}
\hline Mach & $\boldsymbol{R e} / \boldsymbol{f t}\left(\boldsymbol{x} \mathbf{1 0}^{\boldsymbol{6}}\right)$ & $\boldsymbol{P}_{\boldsymbol{T}}(\boldsymbol{p s f})$ & $\boldsymbol{T}_{\boldsymbol{T}}(\boldsymbol{d e g} \boldsymbol{R})$ & $\boldsymbol{q}(\boldsymbol{p s} \boldsymbol{f})$ \\
\hline 2.5 & 2.0 & 1600 & 585 & 410 \\
\hline 3.5 & 2.0 & 2882 & 610 & 324 \\
\hline 4.6 & 2.0 & 4878 & 610 & 221 \\
\hline
\end{tabular}

\section{Test Hardware}

Model Configurations:

All experimental aerodynamic data were obtained on 5\% scaled LAV models designed and fabricated at the NASA Langley Research Center. The model assemblies consisted of four main structural components: a balance adapter, a tower section, a removable nose section, and boost protective cover (BPC) fairing covering the CM (Fig. 7). The balance adapter, fabricated of 13-8 stainless steel, is designed with a precision-fit bore to receive a 5-component flow-through force-and-moment balance (shown in Fig. 7). The tower section bolts to the forward end of the balance adapter and was designed with a variablediameter centerline hole to route high pressure air up to the ACM nozzles. The tower was fabricated from 2024 aluminum and includes external mating surfaces for abort motor nozzles, canards, and a raceway cover. The forward section of the tower was designed to mate to a removable, stainless steel nose piece that allows high pressure air to be fed to 8 individual nozzle blocks (see inset in Fig. 7) that simulate an ACM design condition. The plenum at the aft end of the tower was designed to accomodate three total pressures, one static pressure, and two total temperature measurements. The BPC fairing pieces, modeling both the LAS-605-068 and the ALAS-11 Rev.3c configurations, were fabricated from 6061 aluminum in two-piece, clamshell design. Figure 8 shows a

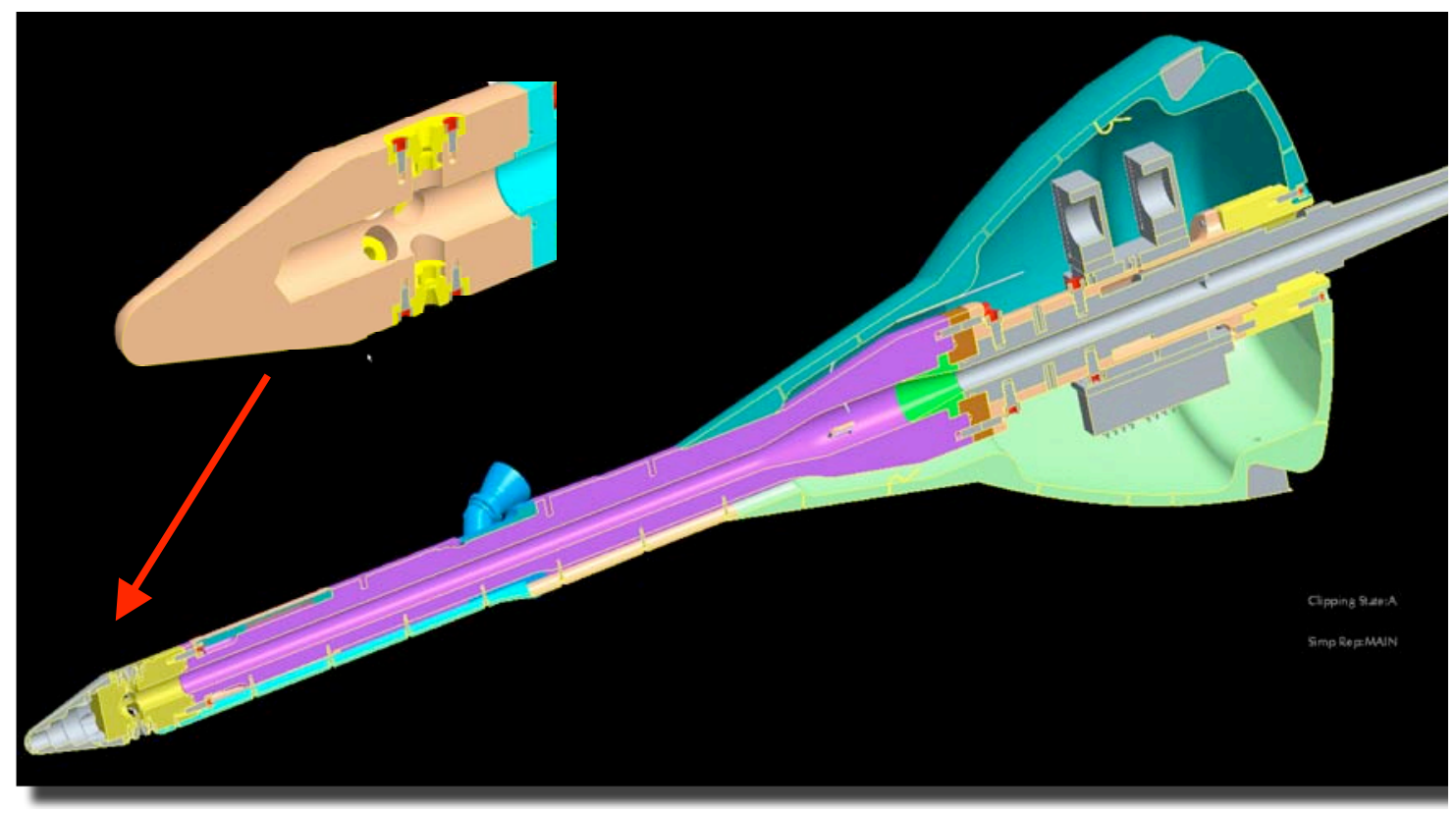

Figure 7. 5\% ACM jet interaction model design schematic. 


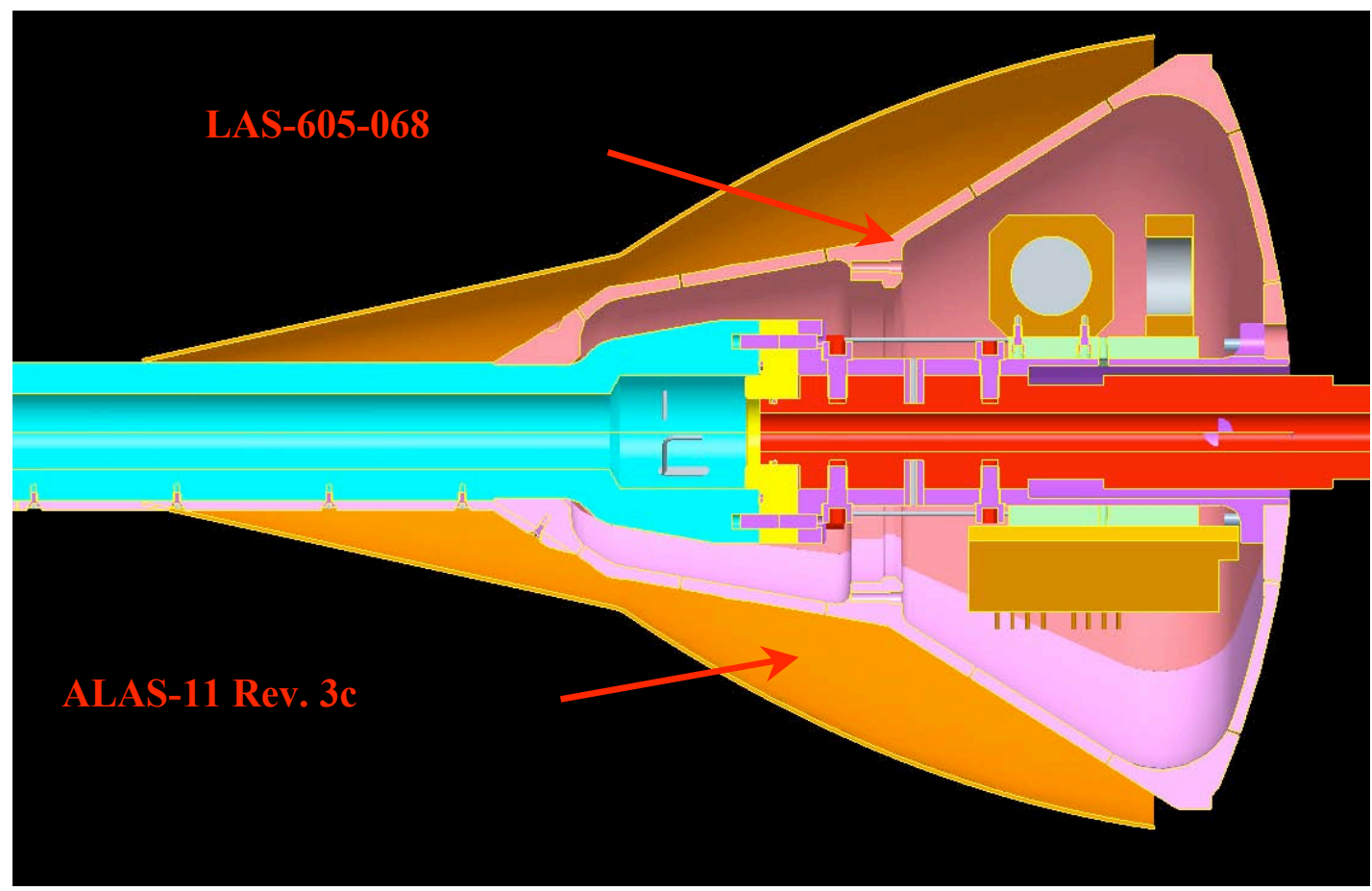

Figure 8. Comparison of lower capsule configurations LAS-605-068 and ALAS-11 Rev. 3c.

comparison of the outer mold lines (OML) for the two LAV configurations.

Both 5\% models had distributed static pressure orfices. All taps are in rings at various longitudinal location at phi angles of $0^{\circ}$ (top), $90^{\circ}, 180^{\circ}$, and $270^{\circ}$. On the ALAS-11

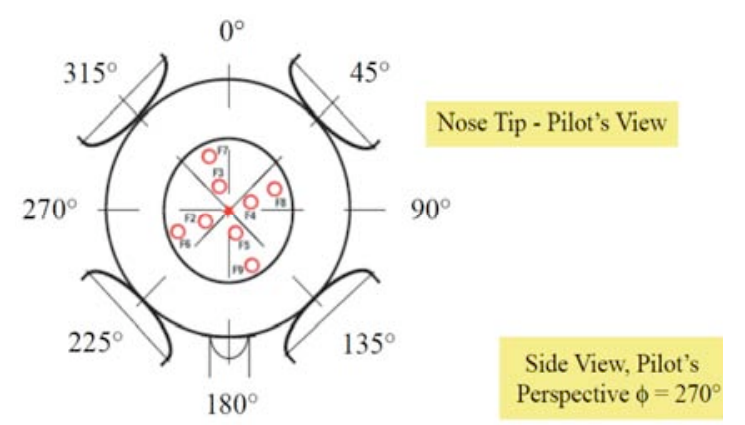
model there are 9 taps on the forward nose piece simulating a Flush Air Data System (FADS) proposed for the flight vehicle. It should be noted that due to a model design oversight, the 9 FADS ports on the test article are rotated $22.5^{\circ}$ from the flight vehicle arrangement. Pressure port layouts are shown in Figures 9 and 10.

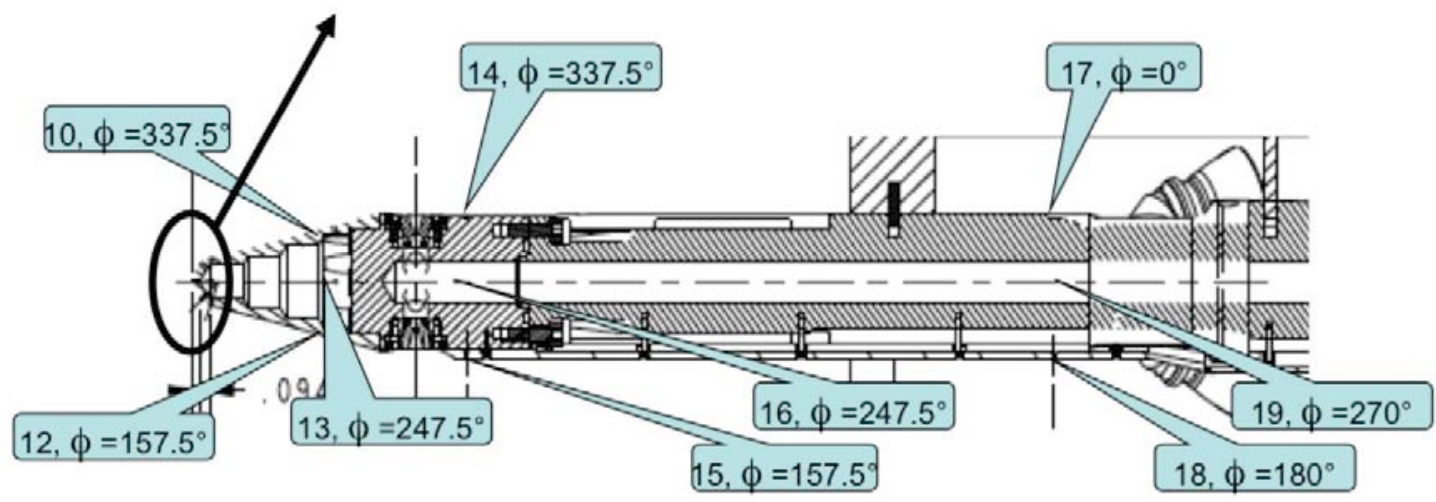

Figure 9. Pressure port layout on the forward tower of the 5\% LAV Model. 


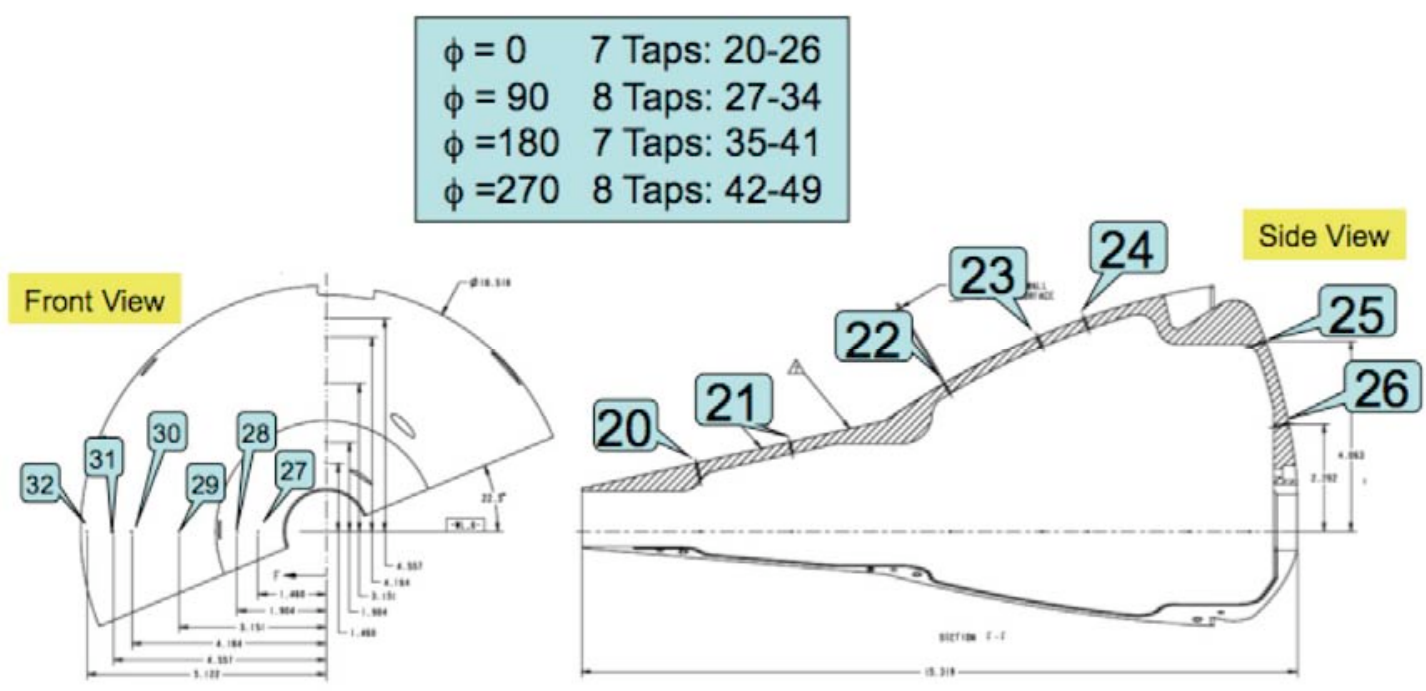

Figure 10. Pressure port layout on the Boost Protective Cover of the 5\% LAV.

The transition scheme used on all previous LAV models was applied to the $5 \%$ ACM models for all test runs (Fig. 11). Mylar 0.011-inch trip dots with 0.1 inch spacing were applied in a circumferential row on the tower 1 inch back from the nose tip, 4 rows running lengthwise down the tower at $+/-22.5 \mathrm{deg},+/-47.5$ deg from top dead center (X pattern from pilot's view), and a circumferential row on the BPC 1 inch forward from the end of the ALAS shroud. Subsequent high fidelity, high Reynolds number testing of the $\mathrm{LAV}^{6}$ showed very small differences with grit and Reynolds number parametrics. Photographs of the 5\% LAV models installed in the ARC UPWT and LaRC UPWT test sections is shown in Figure 12.

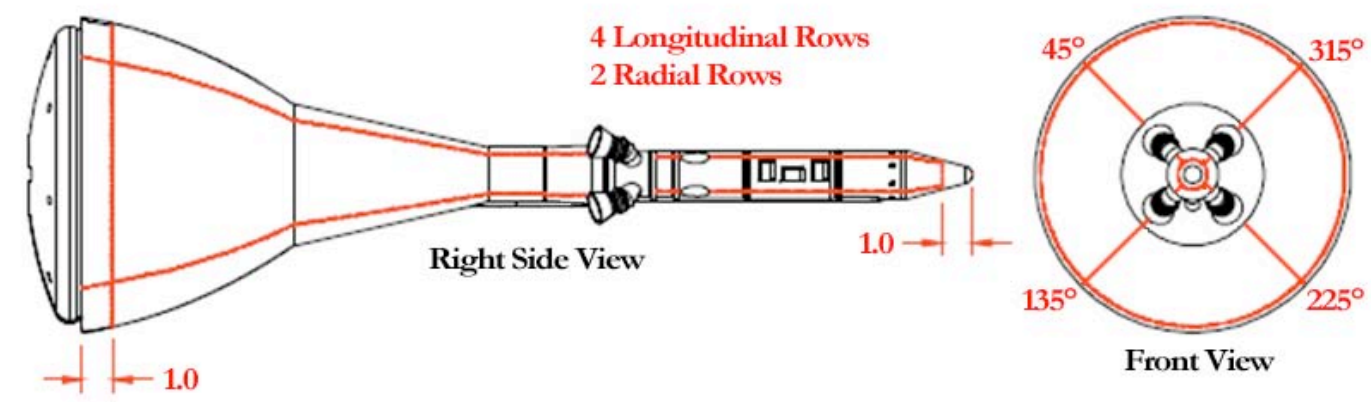

Figure 11. Transition layout for 5\% ACM model.

\section{ACM Nozzles}

In order to simulate different ACM thrust allocations described previously almost 100 interchangeable nozzle blocks were designed in-house at NASA Langley Research Center and fabricated on contract by Modern Machine and Tool in Newport News, VA. Additionally, blanks were fabricated for thrust allocations requiring less than 8 nozzles 

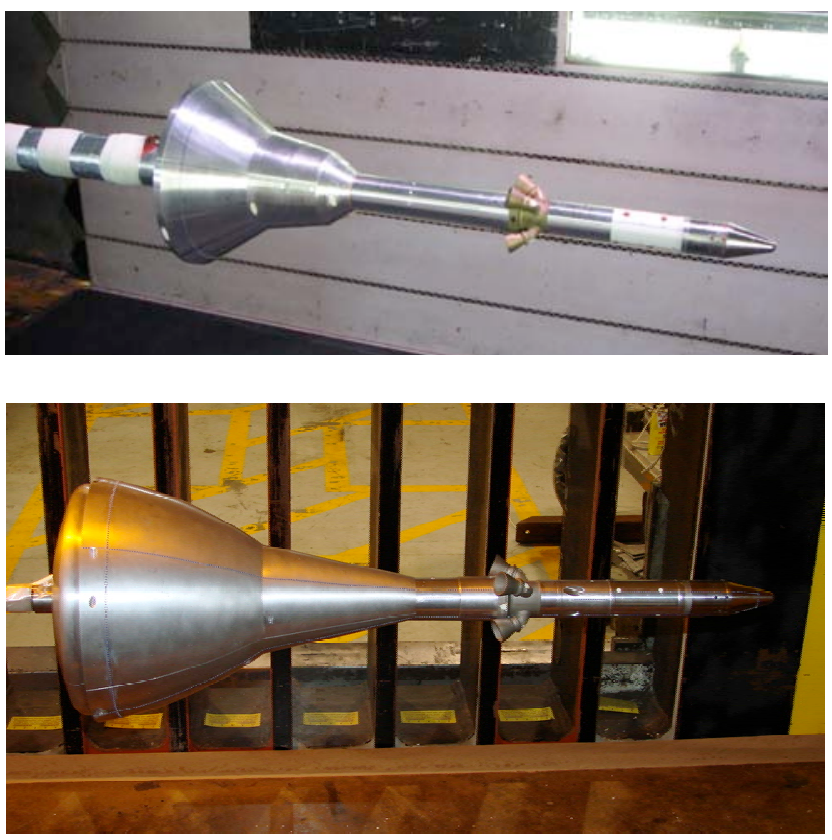

Figure 12. Photograph of 5\% LAS-605-068 model installed in ARC UPWT (top) and the ALAS-11 Rev.3c model installed in LaRC UPWT (bottom).

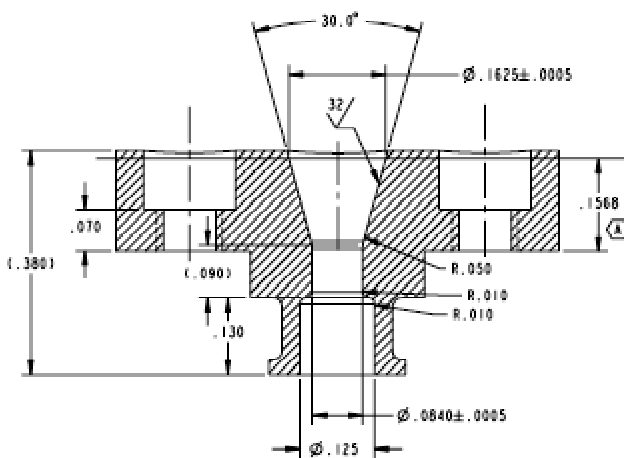

Figure 13. Schematic of a typical nozzle block for the 5\% LAV ACM

firing simultaneously as well as for jet-off runs. A schematic of a typical nozzle block is shown in Figure 13. Nozzle blocks were machined of 17-4 stainless steel with throat diameters ranging from 0.017 in. up to $0.091 \mathrm{in}$. and exit diameters ranging from $0.020 \mathrm{in}$. with a 30 degree included angle.

\section{Instrumentation}

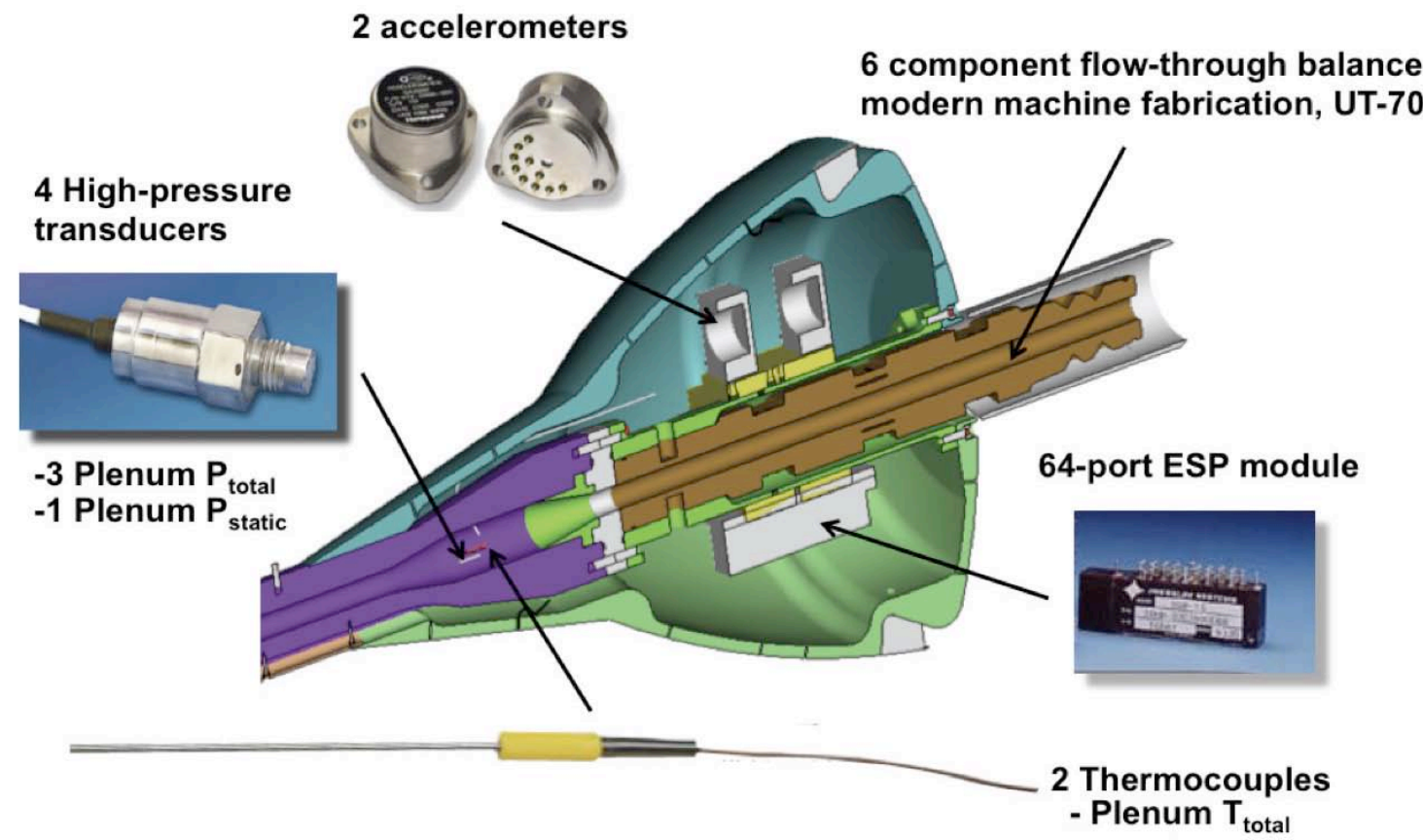

Figure 14. Instrumentation packaging for the 5\% LAV ACM Model. 
Figure 14 is a representative schematic of instrumentation packaging for the $5 \% \mathrm{ACM}$ model for all test entries. The instrumentation and measurements obtained are described below

Aerodynamic Load Measurement:

Flow-through strain gage balances were used to measure aerodynamic forces and moments from which jet interaction increments were calculated. Balance X9512-961, on

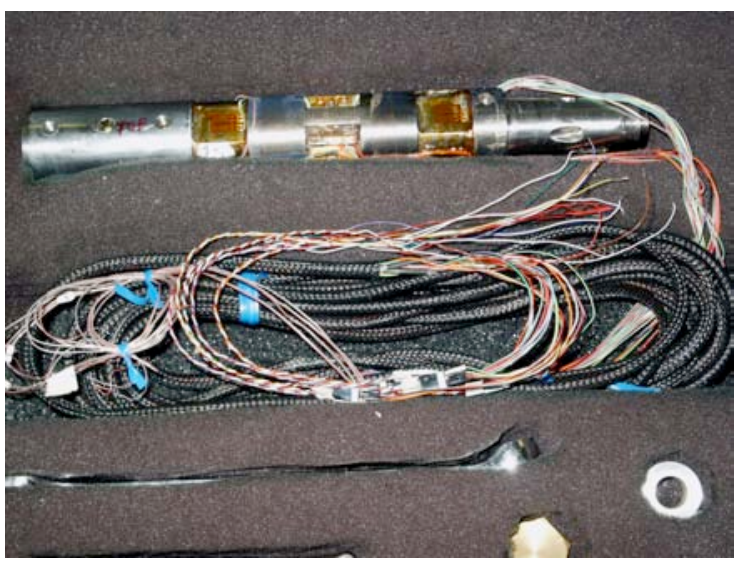

Figure 15. Photograph of 1.5-inch Boeing flow-through balance, X9512-961. loan from the Boeing Company in $\mathrm{St}$ Louis, MO was used for the 59-AA and 75-AA test programs (Fig. 15). The $\mathrm{X} 9512-961$ is a moment-type balance fabricated from 15-5 stainless steel with a nominal maximum external diameter of $1.5 \mathrm{in.}$ and centerline flow-through passage of 0.5 in. diameter. The balance is designed for a maximum excitation voltage of $10 \mathrm{~V}$. When originally fabricated, the balance was a 5component instrument with no axial force measurement capacity. A Poissontype axial force bridge was subsequently added to provide a means to measure full six-component data for unpowered testing. The axial force gauge has been found to have large zero shifts when highpressure air is routed through the balance. The balance has been temperature compensated but no temperature calibration has been conducted either on the original five components or the added axial force component. Temperature sensitivity is suspected as a contributor to the drift problems encountered in axial force during powered testing. Thus axial force recorded during powered testing was not used.

A new 6-component flow-through balance, designated UT-70, was manufactured for

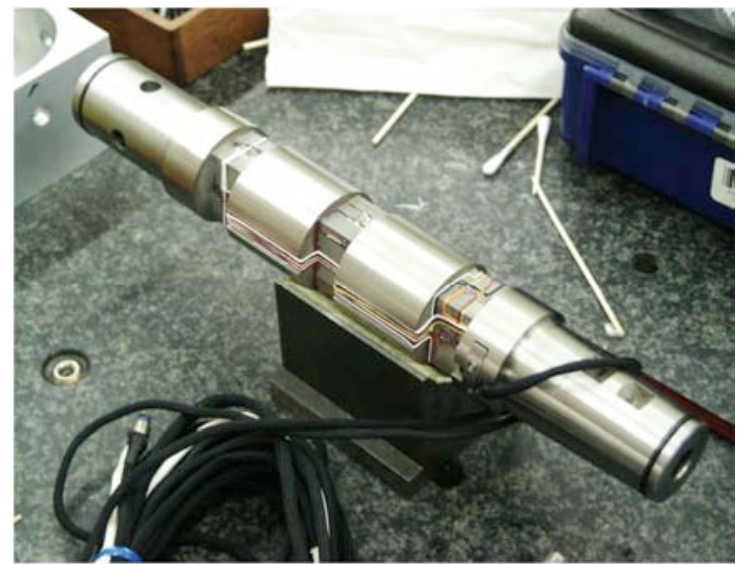

Figure 16. Photograph of 1.5-inch LaRC flow-through balance, UT-70.
LaRC by Modern Machine and Tool for the 76-AA test program. UT-70 is a moment-type balance fabricated from VASCOMAX 300 with a maximum external diameter of 1.75 in. and a centerline flow-through passage of 0.5 in. diameter. The balance was designed for a maximum excitation voltage of $5 \mathrm{~V}$. The axial force gage was assumed to have large zero shifts when high-pressure air was routed through the balance, and axial force measurements made during thrust tares showed poor repeatability with plenum pressure variation. Therefore axial measurements were only 
used for unpowered conditions. The balance gages were temperature compensated but no temperature calibration has been conducted. A photograph of the balance is shown in Figure 16.

Procedures for monitoring balance stability and data uncertainty are described in a subsequent section. Observed variations in balance output were compared to balance accuracies for all relevant balance components based on the $\pm 95 \%$ confidence level from balance calibration reports. These balance uncertainties, and corresponding aerodynamic coefficient uncertainties, for representative flow conditions are also shown in Tables 3 and 4 for both the Boeing and Langley balances.

Table 3. 95\% Confidence Balance Accuracies for the Boeing X9512-961 Balance.

\begin{tabular}{|c|c|c|c|c|c|c|c|}
\hline & NF(Ibs) & AF(Ibs) & PM(in-lbs) & RM(in-lbs) & YM(in-lbs) & SF(Ibs) \\
\hline \multirow{3}{*}{\multicolumn{2}{|c|}{$\begin{array}{r}\text { Maximum Load } \\
\text { Accuracy (\%full-scale) } \\
\text { Accuracy (Load) }\end{array}$}} & 2500 & 760 & 5000 & 500 & 2500 & 2500 \\
\hline & & 0.048 & 0.146 & 0.172 & 0.286 & 0.270 & 0.037 \\
\hline & & 1.19 & 1.11 & 8.59 & 1.43 & 6.74 & 0.93 \\
\hline Mach & $\bar{q}$ q (psf) & $\begin{array}{c}\mathrm{CN} \pm 2 \sigma \\
\text { Accuracy } \\
\end{array}$ & $\begin{array}{c}\mathrm{CA} \pm 2 \sigma \\
\text { Accuracy } \\
\end{array}$ & $\begin{array}{c}\mathrm{CM} \pm 2 \sigma \\
\text { Accuracy }\end{array}$ & $\begin{array}{c}\mathrm{Cl} \pm 2 \sigma \\
\text { Accuracy }\end{array}$ & $\begin{array}{c}\text { Cn } \pm 2 \sigma \\
\text { Accuracy }\end{array}$ & $\begin{array}{c}C Y \pm 2 \sigma \\
\text { Accuracy }\end{array}$ \\
\hline 0.3 & 189 & 0.0118 & 0.0110 & 0.0102 & 0.0017 & 0.0080 & 0.0092 \\
\hline 0.5 & 302 & 0.0073 & 0.0069 & 0.0064 & 0.0010 & 0.0050 & 0.0058 \\
\hline 0.7 & 405 & 0.0055 & 0.0051 & 0.0048 & 0.0008 & 0.0037 & 0.0043 \\
\hline 0.9 & 490 & 0.0046 & 0.0043 & 0.0040 & 0.0006 & 0.0031 & 0.0036 \\
\hline 0.95 & 503 & 0.0045 & 0.0042 & 0.0039 & 0.0006 & 0.0030 & 0.0035 \\
\hline 1.05 & 539 & 0.0042 & 0.0039 & 0.0036 & 0.0006 & 0.0028 & 0.0033 \\
\hline 1.1 & 550 & 0.0041 & 0.0038 & 0.0035 & 0.0006 & 0.0028 & 0.0032 \\
\hline 1.3 & 593 & 0.0038 & 0.0035 & 0.0033 & 0.0005 & 0.0026 & 0.0030 \\
\hline 1.6 & 637 & 0.0035 & 0.0033 & 0.0030 & 0.0005 & 0.0024 & 0.0027 \\
\hline 2 & 629 & 0.0036 & 0.0033 & 0.0031 & 0.0005 & 0.0024 & 0.0028 \\
\hline 2.5 & 582 & 0.0038 & 0.0036 & 0.0033 & 0.0005 & 0.0026 & 0.0030 \\
\hline
\end{tabular}

Table 4. 95\% Confidence Balance Accuracies for the LaRC UT-70 Balance.

\begin{tabular}{|c|c|c|c|c|c|c|c|}
\hline & NF(lbs) & AF(lbs) & PM(in-lbs) & RM(in-lbs) & YM(in-lbs) & SF(lbs) \\
\hline \multirow{3}{*}{\multicolumn{2}{|c|}{$\begin{array}{r}\text { Maximum Load } \\
\text { Accuracy }(\% \text { full-scale) } \\
\text { Accuracy (Load) }\end{array}$}} & 600 & 600 & 6400 & 1200 & 3200 & 600 \\
\hline & & 0.220 & 0.800 & 0.080 & 0.210 & 0.180 & 0.160 \\
\hline & & 1.32 & 4.8 & 5.12 & 2.52 & 5.76 & 0.96 \\
\hline Mach & $\bar{q}$ q (psf) & $\begin{array}{c}\mathrm{CN} \pm 2 \sigma \\
\text { Accuracy }\end{array}$ & $\begin{array}{c}\mathrm{CA} \pm 2 \sigma \\
\text { Accuracy }\end{array}$ & $\begin{array}{c}\mathrm{CM} \pm 2 \sigma \\
\text { Accuracy }\end{array}$ & $\begin{array}{c}\mathrm{Cl} \pm 2 \sigma \\
\text { Accuracy }\end{array}$ & $\begin{array}{c}\mathrm{Cn} \pm 2 \sigma \\
\text { Accuracy }\end{array}$ & $\begin{array}{c}C Y \pm 2 \sigma \\
\text { Accuracy }\end{array}$ \\
\hline 2.5 & 410 & 0.0060 & 0.0219 & 0.0024 & 0.0012 & 0.0027 & 0.0044 \\
\hline 3.5 & 324 & 0.0076 & 0.0277 & 0.0030 & 0.0015 & 0.0034 & 0.0055 \\
\hline 4.6 & 221 & 0.0112 & 0.0406 & 0.0044 & 0.0022 & 0.0049 & 0.0081 \\
\hline
\end{tabular}


It should be noted that the aforementioned balance accuracies represent only the uncertainties associated with the balance itself. This would be a measure of the overall uncertainty on the wind tunnel measurements only in the absence of all other variations. Repeat runs were done throughout the test matrix to provide estimates of within-test repeatability and aerodynamic data obtained in different wind tunnel facilities on different physical models have been analyzed to obtain the most rigorous estimate of overall experimental uncertainty. A detailed uncertainty analyses is outside of the scope of this paper, but the reader is referred to References 7-9 for a comprehensive discussion of uncertainty formulation and results for aerodynamic data generated in the Orion program.

\section{Pressure Measurement:}

All static pressure measurements on the model surface and in the model cavity were made using a commercially available electronically scanned pressure (ESP) module. Miniature electronic pressure scanners are differential pressure measurement units consisting of an array of silicon piezoresistive pressure sensors, one for each pressure port. The ESP module used for this test program, manufactured by Pressure Systems, Inc., is rated for a nominal maximum pressure of \pm 15 psid with an accuracy of $0.05 \%$ of full-scale rating. The differential ESP module was used as an absolute gage by evacuating the reference side of the module using a common vacuum source. One 64-port ESP module was mounted on the balance block inside the model cavity. Flexible pressure tubing with an inside diameter (I.D.) of 0.020 in. was used to connect each surface tap and cavity pressure line to specified ESP module ports.

Two high-pressure transducers, ETM-375 series manufactured by Kulite Semiconductor Products, Inc., were used to measure both total and static pressure levels in the model plenum. The transducers are rated for a nominal maximum pressure of \pm 2500 psia with an accuracy of $0.1 \%$ of full-scale rating. The ETM-375 series transducers utilize a threaded flush metal diaphragm as a force collector, transferring to a piezoresistive sensing element via silicone oil. Both transducers were mounted on the balance block inside the model cavity and connected directly to $0.020 \mathrm{in} . / 0.040$ in diameter tubing routed from the model plenum.

Temperature Measurement:

Two redundant total temperature measurements were made in the plenum of the model using two miniature-style Type K Thermocouples made by Omega, Inc., model KMTXL062. Type $\mathrm{K}$ thermocouples utilize the thermal properties of the two conductors, chromel and alumel, to generate a voltage difference proportional to temperature experienced by the probe. The probe's diameter is 0.062 in and is rated for use at temperatures up to $2400{ }^{\circ} \mathrm{F}$. Quoted accuracy for temperature measurements is approximately $\pm 0.1 \%$ of fullscale output.

Attitude Measurement:

Model angle of attack was measured via two on-board accelerometers. Redundant measurements were made using the Q-flex QA-2000 model manufactured by Honeywell, 
Inc. Angular measurements are produced via deflection of proof-mass and related circuitry. Both accelerometers were mounted in the manufacturer's standard single-axis aluminum housing that attached to the balance block inside the model cavity. Quoted

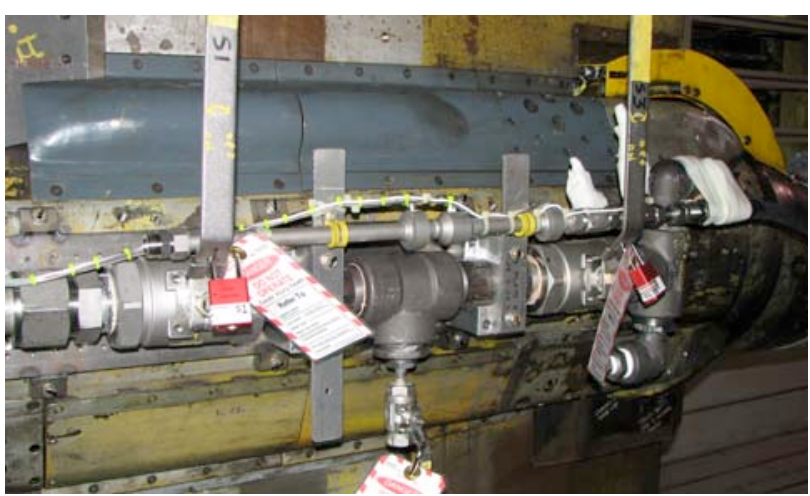

Figure 17. Subcritical venturi installed in ARC UPWT. accuracy for direct angle measurement is approximately $0.01 \mathrm{deg}$.

Mass Flow Measurement:

For testing the ARC UPWT, a specially designed subcritical venturi flow meter was used to measure mass flows delivered to the model from the facility high pressure air system. The flow meter was designed by Flow Systems, Inc. and its primary component is a Herschel-style venturi, built in accordance with ASME fluid meter standards. Upstream of the venturi is a straight 0.75 -inch stainless diameters). Approximately 1.5 inches upstream of the venturi entrance is a fitting allowing measurement of both upstream absolute static pressure as well as a differential measurement with the venturi throat. The absolute static pressure was measured using the Kulite ETM-375 2500 psi transducer described in a preceding section. The differential pressure was measured using a high-accuracy Rosemount 1151DP pressure transducer, calibrated up to 10.8 psi. Manufacturer's specifications list the accuracy of this device at or below $0.25 \%$ of its full-scale range. Static temperature was measured 4.23 in. down stream of the venturi exit using an RTD-85 standard K-type thermocouple used in standard practice by the UPWT Wind Tunnel. Due to facility and fabrication schedule constraints, the venturi flow meter was calibrated post-test. Calibration results showed high losses (low discharge coefficients) at low pressure, low mass flow conditions. This led to higher uncertainty for low-flow cases such as single nozzle thrust tares. Figure 17 shows a photograph of the venturi as mounted on the UPWT support strut.

For the LaRC UPWT test program, a Micro Motion coriolis flow meter (model F050P) was used to measure mass flows delivered to the model from the facility high-pressure air system. The meter was physically located within 10 feet of the model. The maximum operating pressure of the meter was 5,000 psi. The factory calibration was used with a stated accuracy of $0.5 \%$ of full scale in the range from $0.07 \mathrm{lbm} / \mathrm{sec}$ to $4 \mathrm{lbm} / \mathrm{sec}$. The stated minimum flow rate measurable was $0.03 \mathrm{lbm} / \mathrm{sec}$ at $1.1 \%$ accuracy. As a point of reference, only single nozzle calibrations yielded model mass flows less than $0.1 \mathrm{lbm} / \mathrm{sec}$.

Mass flow ranges for the three ACM test programs are provided in a subsequent section along with a discussion of calculated versus measured mass flow issues experienced for both flow meters. 


\section{Experimental Procedures / Data Reduction}

Aerodynamic Data:

In order to obtain aerodynamic jet interaction increments, aerodynamic data had to be obtained for ACM jet-off and jet-on firing conditions for both wind-off and wind-on wind tunnel conditions.

Unpowered Aerodynamic Data: Wind-on, jet-off data were used to generate, via standard UPWT data reduction, static aerodynamic data for the two LAV configurations tested. All data were taken in a pitch-pause mode and were corrected for model weight, buoyancy, cavity, and sting effects. Balance wind-off zeros were recorded before and after sets of wind-on runs and monitored for drift. Given the known balance sensitivity to temperature, careful attention was paid to acquiring wind-on data and wind-off zeros over as narrow range of balance temperatures as possible. This requirement led to development of a balance "conditioning" routine for recording proper wind-off zero points. At the beginning of a shift or a new configuration installation, the model and balance were subjected to wind-on, jet-on test conditions to heat or cool the balance to temperatures observed during wind-on test blocks. This was shown to dramatically improve repeatability for several balance components.

Static Thrust Tares: Jet-on, wind-off data, referred to as static thrust tares, were taken to allow removal of pure jet thrust effects from the data in order to isolate jet interaction effects. Since pressures at the exit of these small ACM nozzles could not be measured, nozzle pressure ratio (NPR) for these tests was defined as the ratio of the total pressure $\left(\mathrm{P}_{\mathrm{T}}\right)$ in the model plenum to the free stream static pressure $\left(\mathrm{P}_{\text {ambient }}\right)$. (Note that propulsion literature defines NPR as $\mathrm{P}_{\text {total, throat }} / \mathrm{P}_{\text {static, exit }}$ but there was no physical way to measure the true throat or exit pressures.) For CAP Tests in the ARC UPWT (59-AA and 75-AA) it was this parameter that was matched for thrust removal from jet-on, wind-on runs. Because free stream pressure varied for different Mach and Reynolds number test conditions, it was necessary to generate static thrust tares over a range of NPR values corresponding to the matrix of free stream test condition and nozzle thrust levels tested. These balance force and moment data as a function of NPR were input as a curve-fit table look-up in the data reduction and thus thrust removal was done as function of NPR. The thrust tares as a function of NPR showed large hysteresis effects assumed to be a function of temperature, and a great deal of engineering judgment was applied to generate curve fits. When testing at the higher supersonic Mach numbers in the LaRC UPWT (CAP Test 76-AA) the wind-on NPR range was much higher (in some cases an order of magnitude higher) than could be obtained in a static thrust tare. A concern regarding inaccuracies in extrapolation caused the test team to reexamine thrust removal. It was decided to formulate thrust removal as a function of measured chamber pressure with a calculated correction for the difference in NPR between static and wind-on conditions.

Examining the thrust equation:

$$
F=\left[\dot{m} \cdot V_{\text {exit }}+\left(P_{\text {exit }}-P_{\text {ambient }}\right) \cdot A_{\text {exit }}\right] \cdot C f g
$$


It is observed that nozzle internal flow parameters (chamber pressure, mass flow, nozzle geometry and thus exit flow velocity) are the same for wind-off thrust tares and wind-on powered runs. Thus the only correction to a wind-off thrust tare required is the difference in the static pressure term between wind-on and wind-off conditions. Because the pressure component acts along the axis of the nozzle, normal and side force load contributions must be calculated. Also important to note is that due to the nozzle scale (very small $\mathrm{A}_{\text {exit)}}$ ), these pressure term contributions to the overall nozzle thrust was shown to be much smaller than the momentum component and typically 1-2 orders of magnitude smaller than the balance resolution. Thrust removal calculations based on chamber pressure matching eliminated the potentially large extrapolation errors seen when scaling on NPR and generated repeatable, linear results that were much less sensitive to temperature. Thus the above thrust removal philosophy was adopted as the preferred method for powered testing in the Orion program.

Powered Aerodynamic Data: Jet-on, wind-on 5-component aerodynamic data were collected over a range of test conditions described in a subsequent section. Powered data were acquired and corrected similarly to the static aerodynamic data described above with the addition of a thrust removal correction term obtained from the appropriate static thrust tare run. Thus all final facility data files contain powered data with all jet thrust effects removed.

ACM Jet Aerodynamic Interaction Increments: Based on the above definitions and corresponding data reduction, ACM jet interaction increments were calculated post-test by subtracting a wind-on, jet-off run and a wind-off, jet-on run from a wind-on, jet-on run for the corresponding configuration and test conditions. Thus for all five balance components, the jet interaction increment can be described by the following equation:

$$
\left.\left.\mathrm{C}_{\mathrm{x}}(\text { jet increment })=\mathrm{C}_{\mathrm{x}}(\text { wind-on, jet-on })-\mathrm{C}_{\mathrm{x}} \text { (wind-off, jet-on }\right)-\mathrm{C}_{\mathrm{x}} \text { (wind-on, jet-off }\right)
$$

$\mathrm{C}_{\mathrm{x}}$ is any one of 5 aerodynamic coefficients calculated based on measured balance data with appropriate corrections described above.

Thrust Ratio Calculations: The re-evaluation of thrust removal methods described above also to led to a similar re-evaluation of total thrust calculations for determination of thrust ratio. For a given set of nozzle geometries with a given internal mass flow, pressure, and temperature, the calculated interaction increments described above are associated with a specific value of thrust ratio. Initially the wind tunnel model's calculated thrust ratio was based on the following:

Ideal thrust is defined as:

$$
F_{\text {ideal }}=\dot{m}\left[\left(2 R T_{T}\right)(\gamma /(\gamma-1.0))(1.0-N P R)^{((1.0-\gamma) / \gamma)}\right]^{0.5}
$$

For a given thrust allocation $\mathrm{F}_{\text {ideal }}$ is seen to be a function of the mass flow (measured via venturi or coriolis flow meter described above), plenum total temperature, and NPR as defined earlier. 
Actual thrust produced will always be lower than $F_{\text {ideal }}$ due to losses in the nozzles. Due to the lack of a true nozzle calibration facility, an estimate of the loss factor was first obtained by doing single nozzle thrust tares and comparing balance outputs to ideal thrust calculations. These single nozzle thrust tares, initially plotted as a function of NPR, were not well-behaved data and required significant amount of engineering judgment to create loss estimates. An additional problem was identified when measured values of mass flow from both the venturi and the coriolis meter were generally higher than idea calculations based on plenum total pressure and temperature (assuming choked conditions in the nozzle throats), the delta widening with increasing chamber pressure. Mass flows greater than ideal are not physically possible and the differences were far too large to be explained by instrumentation bias errors.

Given the large discrepancies with this set of internal flow measurements, the internal flow path was modeled and CFD solutions using the STAR-CCM code ${ }^{8}$ were obtained based on several sets of measured plenum conditions for several thrust allocations/nozzle geometries. The summary of this work was that by using a 5-6\% nozzle loss factor, the CFD was in excellent agreement with both the balance data (i.e. measured thrust) and the mass flows calculated from plenum conditions. Although there is still no complete explanation to date as to why both mass flow meters would consistently over-predict mass flow (upstream leaks and/or temperature effects on calibrations are possible causes), it was decided to use calculated mass flow values and a 5-6\% loss factor for all thrust ratio calculations.

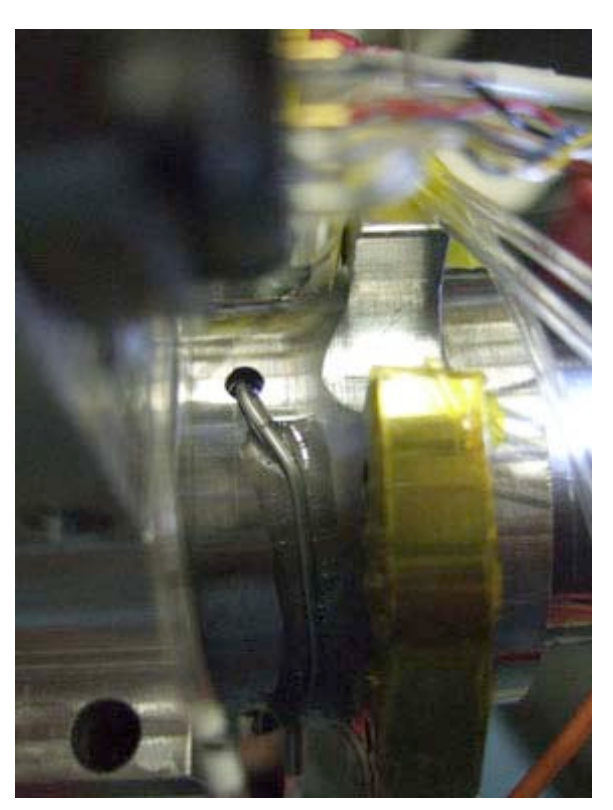

Figure 18. Cavity pressure tube entering balance adapter on 5\% LAV model.
Static Pressure Data:

As shown in Figures 9 and 10, static pressures were measured at multiple locations on the BPC of both the LAS-605-068 and the ALAS-11-Rev3c configurations. Cavity pressures were also measured at 4 locations in the sting cavity. Modifications were made to the balance adapter piece to enable pressure tubing to run directly from the ESP module into 4 holes drilled at the aft portion of the balance sleeve. The hole in the vicinity of the exit-cabling notch is shown in Fig. 18. Static pressures inside the BPC section were monitored via two additional pressure tubes placed in the interior of the BPC.

Both a cavity and a sting correction were applied to the unpowered and powered data as applicable. The cavity correction is an internal correction to account for the missing axial force contribution of the cavity pressure across the sting area. This axial force component is calculated using an average of 
the four measured cavity pressures times the sting cross-sectional area. The net cavity correction acts in the positive axial force direction. The sting correction is applied to the axial force data to account for the missing axial force due to absence of model base area. (Pitching moment and yawing moment would also be corrected for a configuration with an offset center of gravity in the pitch and yaw planes.) The sting correction was calculated using an average of the 4 closest base pressures to the sting times the sting crosssectional area and acts in the negative axial force direction. It is recognized that this is by no means a rigorous measure of sting interference effects required for aerodynamic performance testing. Calculation of cavity and
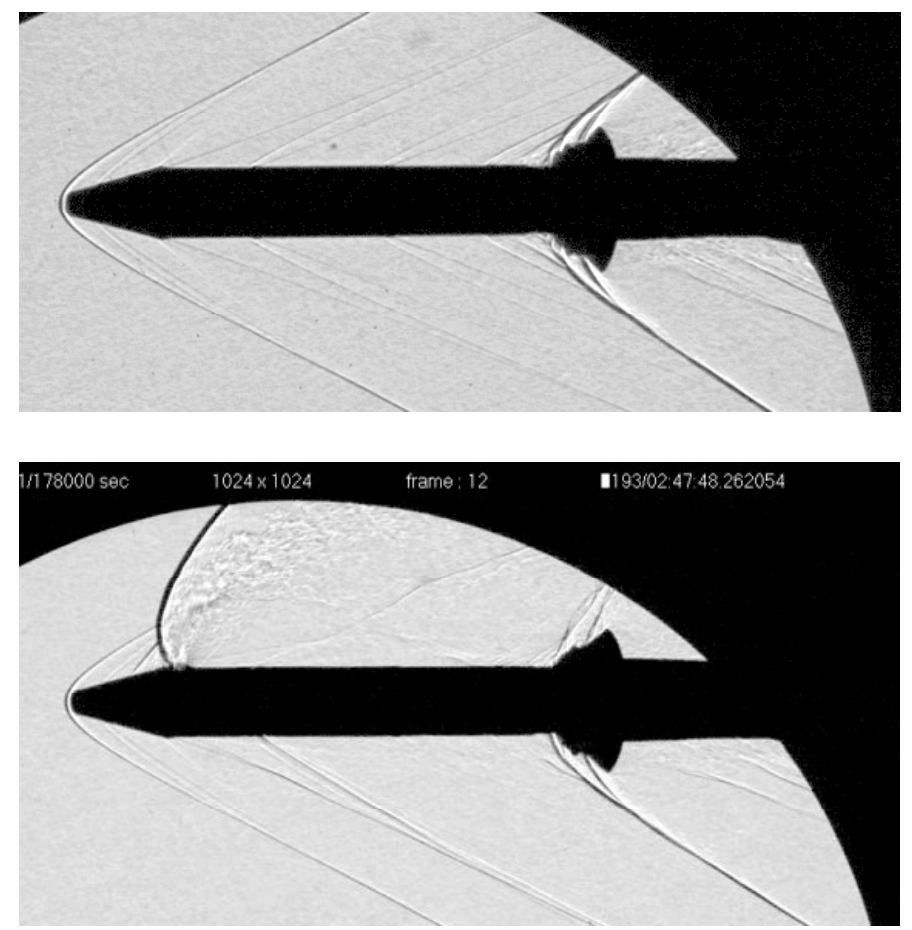

Figure 19. Schlieren images for maximum thrust, jet-on conditions at $M_{\infty}=2.5, T R=0.1, \alpha=0^{\circ}, \beta=0^{\circ}$.

sting effects based on the measured pressures and the aforementioned assumptions show both corrections to be generally small, opposing effects for this configuration.

\section{Schlieren Data:}

Conventional Schlieren image data were obtained for all tunnel conditions, jet firings, and model attitudes tested. Figure 19 shows sample Schlieren images for jet-off and jeton conditions at $\mathrm{M}=2.5, \alpha=0 \mathrm{deg}, \beta=0 \mathrm{deg}$. Movement of the model in the test section relative to the location of the Schlieren windows precluded capturing the entire model flow field for certain test conditions. Installation schematics will be included in the full paper to show optical access for both the ARC and LaRC UPWT. Details of facility Schlieren systems can be found in References 4-6.

\section{Test Parameters}

Unpowered and powered data for two proposed LAV configurations were obtained over a range of attitude, flow, and configuration parameters to obtain jet interaction increments as discussed in preceding sections. The LAV aerodynamic coordinate system used for the experimental data is shown in Figure 20. Tower forward is 0 deg angle of attack; heat shield forward is $180 \mathrm{deg}$ angle of attack. The raceway of the model is located at the 


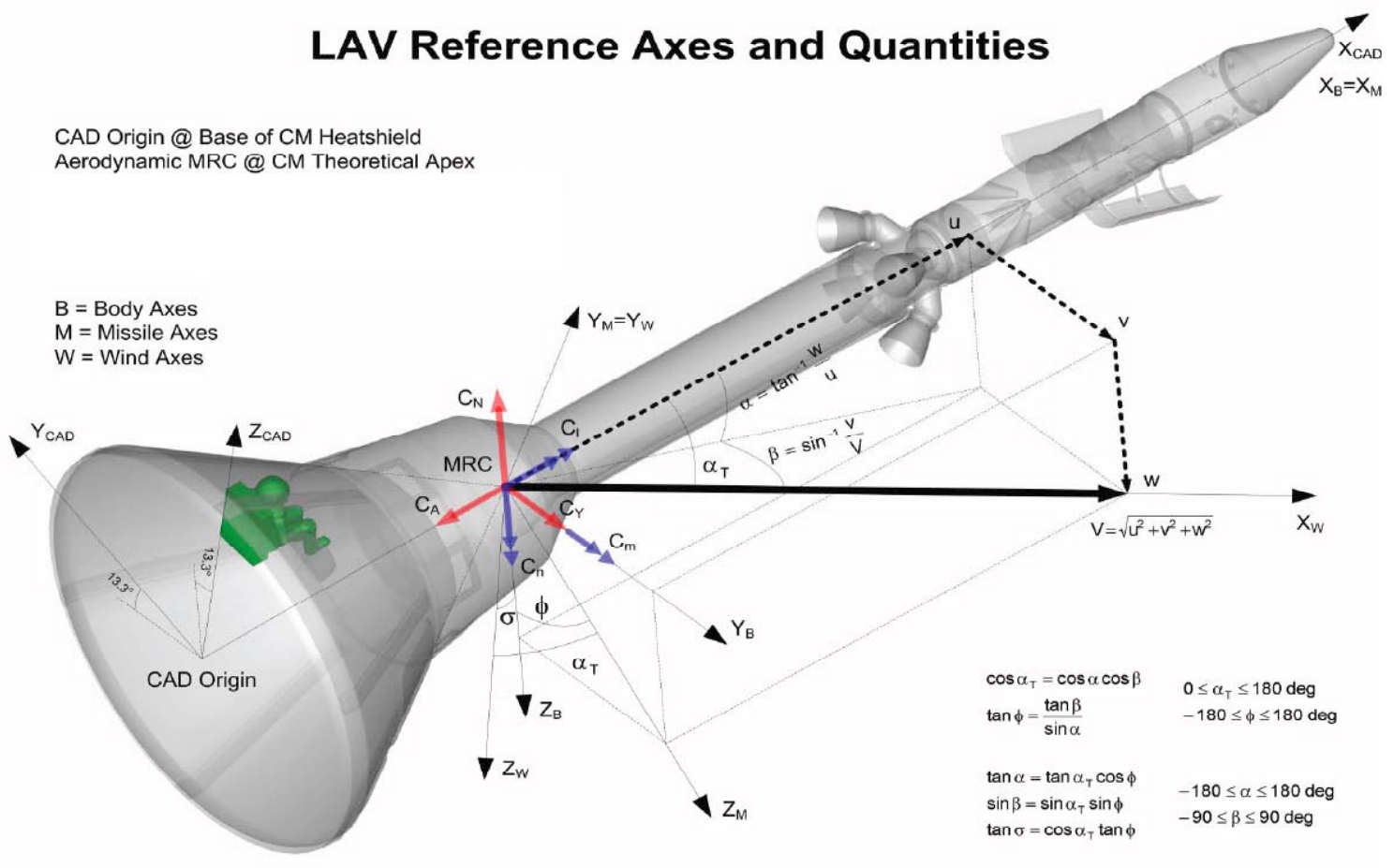

Figure 20. Wind tunnel LAV Aerodynamic coordinate system.

bottom of the forward tower, i.e. on the windward side of the tower for angle of attack 0$180 \mathrm{deg}$. The unpowered abort motors are located on midsection of the forward tower at circumferential locations of 45, 135, 225, and $315 \mathrm{deg}$. (relative to pilots view). The

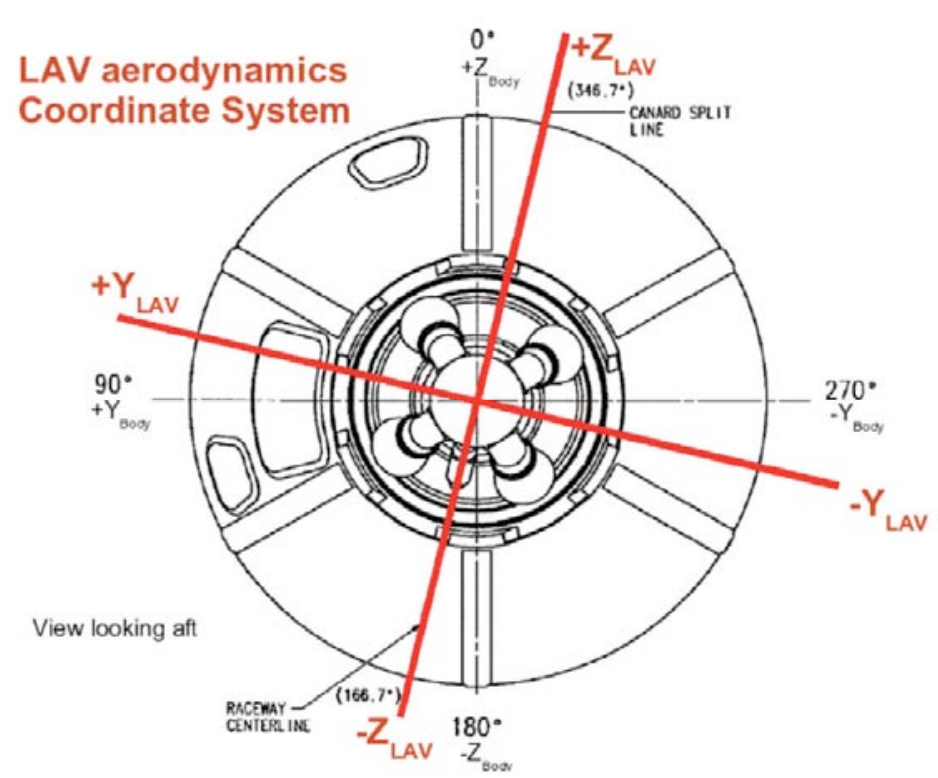

Figure 21. Flight vehicle LAV Aerodynamic Coordinate System. current flight vehicle coordinate system is rotated 13.3 deg. relative to the aerodynamic coordinate system for the flight vehicle to create symmetry and aid wind tunnel testing (Fig. 21).

Table 5 shows a complete listing of the attitude, flow, and configuration parameters for CAP Tests 59-AA, 75-AA, and 76AA. Over 3700 runs were obtained to populate the ACM jet interaction aerodynamic database for the LAS-605-068 and ALAS-11 Rev. 3c configurations. 
Table 5. Summary of test parameters for ACM JI aerodynamic data.

\begin{tabular}{|c|c|c|c|}
\hline Parameter & Test 59-AA & Test $75-A A$ & Test 76-AA \\
\hline OML Geometry & $\begin{array}{c}\text { LAS-605-068 } \\
\text { ALAS-11 Rev.3c }\end{array}$ & ALAS-11 Rev.3c & ALAS-11 Rev.3c \\
\hline Raceway & On/Off & $\mathrm{On}$ & On \\
\hline Canards & On/Off & Off & Off \\
\hline Mach Number & 0.3 to 1.3 & 0.3 to 2.5 & 2.5 to 4.6 \\
\hline Reynolds Number & $2 \times 10^{6}$ to $4 \times 10^{6} / \mathrm{ft}$ & $3 \times 10^{6} / \mathrm{ft}$ & $2 \times 10^{6} / \mathrm{ft}$ \\
\hline Angle of Attack & $-5^{\circ}$ to $+25^{\circ}$ & $-15^{\circ}$ to $+15^{\circ}$ & $-16^{\circ}$ to $+16^{\circ}$ \\
\hline Angle of Sideslip & $-10^{\circ}$ to $+10^{\circ}$ & $-10^{\circ}$ to $+10^{\circ}$ & $-10^{\circ}$ to $+10^{\circ}$ \\
\hline Angle of Roll & $0^{\circ}$ & $0^{\circ}$ & $0^{\circ}$ \\
\hline Chamber Pressure & 500 to $2800 \mathrm{psi}$ & 500 to $2800 \mathrm{psi}$ & 800 to $3200 \mathrm{psi}$ \\
\hline Mass Flow & $\sim 0.1$ to $0.6 \mathrm{lbm} / \mathrm{sec}$ & $\sim 0.1$ to $0.6 \mathrm{lbm} / \mathrm{sec}$ & $\sim 0.1$ to $0.6 \mathrm{lbm} / \mathrm{sec}$ \\
\hline Thrust Allocations & $\begin{array}{l}\text { Boost, Sustain } \\
\text { Null to Max }\end{array}$ & $\begin{array}{l}\text { Boost, Sustain } \\
\text { Null to Max }\end{array}$ & $\begin{array}{l}\text { Boost, Sustain } \\
\text { Null to Max }\end{array}$ \\
\hline
\end{tabular}

\begin{tabular}{l|l|l|l} 
Runs & Over 1500 & Over 1700 & Over 500
\end{tabular}

Thrust Allocations:

The eight ACM thrusters are designed to provide the required net thrust in any direction to control the LAV as described previously. The range of thrust ratios (TR) tested was defined as a function of Mach number by the abort trajectories shown in Figure 22. Numerical values of TR are ITAR-controlled and not shown. These curves were

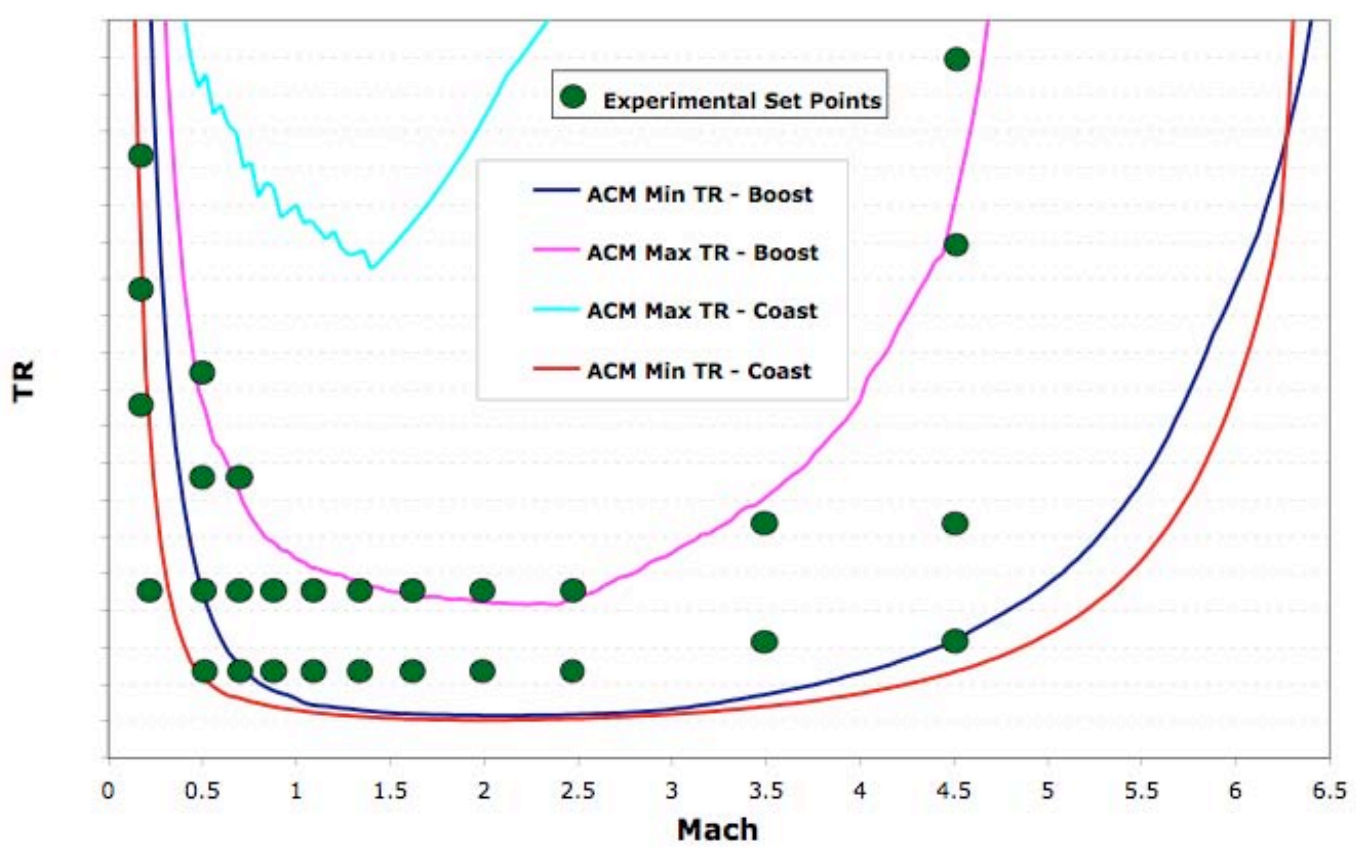

Figure 22. Monte Carlo LAV trajectory simulations showing thrust ratio as a function of Mach number. 
generated from Monte Carlo guidance, navigation, and control (GN\&C) simulations updated throughout the course of the test program, and they vary with LAV trajectory (altitude/dynamic pressure) and motor performance (propellant temperature). The data can be viewed in two sets, one corresponding to the boost phase and the other to the coast phase for a typical launch abort sequence. During the boost phase the abort motors operate at a higher internal pressure $(\sim 2,000 \mathrm{psi})$ as the LAV accelerates away from the launch vehicle. During the coast phase a lower pressure $(\sim 700 \mathrm{psi})$ is maintained for a longer period of time as the LAV coasts and re-orients prior to CM free flight. The two curves for each phase correspond to the predicted ACM engine performance envelope. Both sets of curves were used to bound the minimum and maximum thrust ratios used for the three test programs. Circles represent the approximate thrust ratios tested experimentally. Maximum TR values at the highest and lowest Mach numbers could not be attained due to model chamber pressure limitations.

In order to characterize the jet interactions over the $\mathrm{ACM}$ performance envelope and
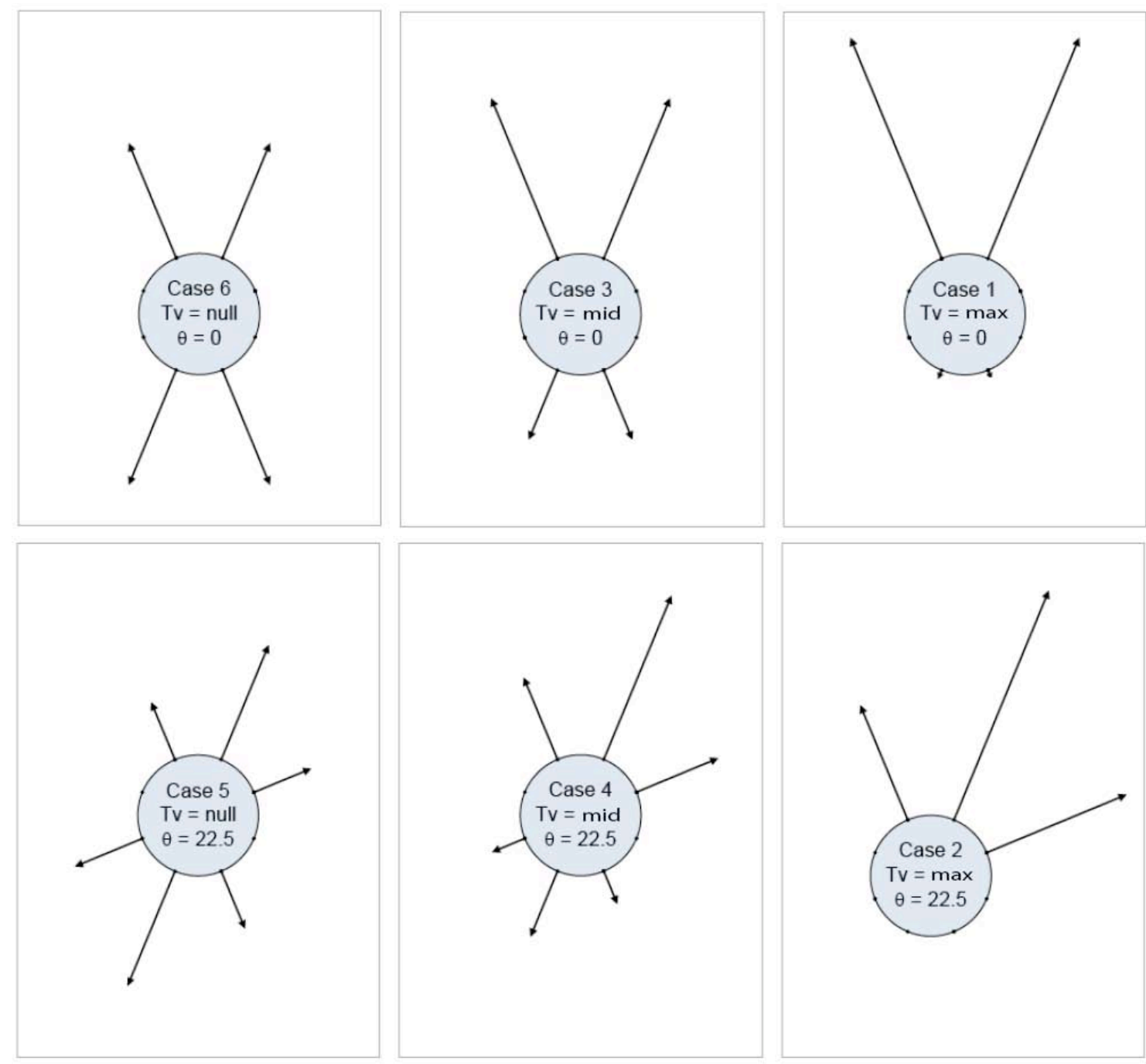

Figure 23. Notional thrust allocation diagrams for max, mid, and null thrust allocations for off-axis and on-axis firings. 
corresponding abort trajectories, a series of thrust allocations were tested. Figure 23 shows a schematic representation of six characteristic thrust allocations corresponding to the max, mid, and null thrust levels. Lines emanating from specific ACM nozzle locations are notionally proportional to the simulated thrust output. The top three simulated allocations in Figure 23 represent off-axis cases where net-thrust directions do not align with a nozzle location. The lower three allocations correspond to on-axis firings. Thrust levels corresponding to boost and coast phases were simulated in the test program by varying the thrust ratio for the same set of physical nozzles. In tests 75-AA and 76-AA, a limited number of "over-performing" and "under-performing" thrust allocations were run corresponding to ACM propellant delivering a higher or lower total thrust than the nominal values shown in Figure 22. Detailed thrust allocation diagrams and related parameters can be found in CAP program test reports ${ }^{9,10,11}$.

Nozzle configurations used to produce the above thrust allocations could be installed in different orientations to produce resultant thrust vectors every 22.5 degrees. Due to tunnel occupancy limitations each thrust allocation could not be tested for all firing directions on all configurations. Effective coverage for the design space was significantly augmented based model symmetry in the beta plane and alpha symmetry in the test matrix where appropriate. Table 6 shows a coverage summary from Test 59-AA for the LAS-605-068 configuration tested in the UPWT 11-FT. Only firings from 0 deg to $180 \mathrm{deg}$ needed to

Table 6. Summary of ACM thrust allocation coverage for LAS-605-068 from Test 59-AA in the UPWT 11-FT.

\begin{tabular}{|c|c|c|c|c|c|c|c|c|c|}
\hline$\theta_{\mathrm{r}}=$ & $0^{\circ}$ & $22.5^{\circ}$ & $45^{\circ}$ & $67.5^{\circ}$ & $90^{\circ}$ & $112.5^{\circ}$ & $135^{\circ}$ & $157.5^{\circ}$ & $180^{\circ}$ \\
\hline \multicolumn{10}{|c|}{ LAS-605-068 Baseline } \\
\hline Max Thrust & Tested & Tested & Tested & $\begin{array}{l}\text { Not } \\
\text { Tested }\end{array}$ & Tested & Tested & $\begin{array}{l}\text { Not } \\
\text { Tested }\end{array}$ & Tested & Tested \\
\hline Mid Thrust & Tested & $\begin{array}{l}\text { Not } \\
\text { Tested }\end{array}$ & Tested & $\begin{array}{l}\text { Not } \\
\text { Tested }\end{array}$ & Tested & $\begin{array}{l}\text { Not } \\
\text { Tested }\end{array}$ & $\begin{array}{l}\text { Not } \\
\text { Tested }\end{array}$ & Tested & Tested \\
\hline Null Thrust & Tested & $\begin{array}{l}\text { Not } \\
\text { Tested }\end{array}$ & Tested & $\begin{array}{l}\text { Not } \\
\text { Tested }\end{array}$ & Tested & Tested & $\begin{array}{l}\text { Not } \\
\text { Tested }\end{array}$ & Tested & Tested \\
\hline \multicolumn{10}{|c|}{ LAS-605-068 with Canards } \\
\hline Max Thrust & Tested & $\begin{array}{l}\text { Not } \\
\text { Tested }\end{array}$ & $\begin{array}{l}\text { Tested } \\
\text { at } 315^{\circ}\end{array}$ & $\begin{array}{l}\text { Tested } \\
\text { at } 292.5^{\circ}\end{array}$ & $\begin{array}{l}\text { Tested } \\
\text { at } 270^{\circ}\end{array}$ & $\begin{array}{l}\text { Not } \\
\text { Tested }\end{array}$ & $\begin{array}{l}\text { Not } \\
\text { Tested }\end{array}$ & $\begin{array}{l}\text { Not } \\
\text { Tested }\end{array}$ & $\begin{array}{l}\text { Not } \\
\text { Tested }\end{array}$ \\
\hline Mid Thrust & $\begin{array}{l}\text { Not } \\
\text { Tested }\end{array}$ & $\begin{array}{l}\text { Not } \\
\text { Tested }\end{array}$ & $\begin{array}{l}\text { Not } \\
\text { Tested }\end{array}$ & $\begin{array}{l}\text { Not } \\
\text { Tested } \\
\end{array}$ & $\begin{array}{l}\text { Not } \\
\text { Tested }\end{array}$ & $\begin{array}{l}\text { Not } \\
\text { Tested }\end{array}$ & $\begin{array}{l}\text { Not } \\
\text { Tested }\end{array}$ & $\begin{array}{l}\text { Not } \\
\text { Tested }\end{array}$ & $\begin{array}{l}\text { Not } \\
\text { Tested }\end{array}$ \\
\hline Nul & Tested & $\begin{array}{l}\text { Not } \\
\text { Tested }\end{array}$ & $\begin{array}{l}\text { Not } \\
\text { Tested }\end{array}$ & $\begin{array}{l}\text { Not } \\
\text { Tested }\end{array}$ & Tested & Tested & Tested & $\begin{array}{l}\text { Not } \\
\text { Tested }\end{array}$ & Tested \\
\hline
\end{tabular}

Table 7. Summary of ACM thrust allocation coverage for ALAS 11-Rev 3c.

\begin{tabular}{|c|c|c|c|c|}
\hline Allocation & Test 59-AA & Test 75-AA & Test 75-AA & Test 76-AA \\
& ARC 11-FT & ARC 11-FT & ARC 9x7-FT & LaRC Leg II \\
\hline Max - Nominal & Every $90^{\circ}$ & Every $22.5^{\circ}$ & Every $22.5^{\circ}$ & Every $22.5^{\circ}$ \\
\hline Null - Nominal & Every $90^{\circ}$ & Every $45^{\circ}$ & Every $22.5^{\circ}$ & Every $22.5^{\circ}$ \\
\hline Max - Over-performing & Not tested & Every $45^{\circ}$ & Every $45^{\circ}$ & Every $90^{\circ}$ \\
\hline Null - Over-performing & Not tested & Not tested & Every $90^{\circ}$ & Not tested \\
\hline Max - Under-performing & Not tested & Not tested & Every $45^{\circ}$ & Not tested \\
\hline Null - Under-performing & Not tested & Not tested & Every $45^{\circ}$ & Not tested \\
\hline
\end{tabular}


be tested, as data from 180 deg to 337.5 could be calculated based on model symmetry in the beta plane. Since the angle of attack range for 59-AA was -5 to +25 degrees, symmetry in the pitch plane could be checked for angle of attack between -5 and +5 for appropriate pairs of allocations. Table 7 shows a coverage summary from 4 test-section entries for the ALAS-11-3c. The angle of attack range for 75-AA and 76-AA was -15 to +15 degrees, thus alpha symmetry was used to increase effective coverage with less configurations.

\section{Sample Results}

\section{Overview}

Given the complexity of attitude control motor operations and the potential for ACM jet plumes to produce highly non-linear control amplifications or attenuations, an extensive jet interaction aerodynamic database is required to characterize resulting changes in LAV flight control characteristics. With three complex test programs generating close to 4000 wind tunnel runs for two LAV configurations over a wide range of test parameters, the volume of data produced was immense. In addition to integrated aerodynamic data, discrete surface pressure were used for CFD validation and to gain and understanding of localized interaction effects. A comprehensive presentation of this data would be in no way possible given the scope of this work. Additionally, Orion program requirements dictate that these data be restricted by ITAR regulations; thus data scales for jet interaction increments or thrust ratio values cannot be presented. Samples of non-scaled jet interaction increment data for both the LAS-605-068 and the ALAS-11 Rev 3c configurations are presented below as well as a facility-to-facility data comparison.

\section{LAS-605-068 Configuration}

With longitudinal control of primary importance for LAV trajectories, Figures 24(a) 24(c) show ACM pitching moment jet interaction data $\left(\Delta \mathrm{Cm}_{\mathrm{ACM}}\right)$ for the LAS-605-068 configuration at Mach 0.7. These data are presented without increment magnitude and as a function of model angle of attack for a range of non-dimensional thrust ratios. Each figure shows data for three characteristic thrust allocations described earlier - max, mid, null - at three firing directions, noted by azimuth angle and compass designations in the upper corner of the figure. For clarity and consistency of presentation, the plots axes for all allocations and all firing directions are shown. Empty plot grids indicate that data were not collected for these test conditions. Figure 24(a) shows data for azimuth angles of $0^{\circ}, 22.5^{\circ}$, and $45^{\circ}$. The large diagram at the top of the figure shows these three resultant thrust directions. The small diagrams above each of the nine plot axes show approximate pictorial representations of the firing configuration and orientation for each allocation. Figures 24(b) and 24(c) are similarly formatted and cover azimuth angle sets $67.5^{\circ}, 90^{\circ}, 112.5^{\circ}$ and $135^{\circ}, 157.5^{\circ}, 180^{\circ}$, respectively. As expected, these data are quite non-linear for all allocations. For all azimuth angles and nozzle arrangements, interaction strength increases with increasing thrust ratio. Interactions are generally seen to be at a minimum at zero angle of attack, with a few exceptions where jets may have been shielded from the freestream flow by the model and high angles of attack. With both 
localized and far field disturbance potential for each of the firing jets, it is very difficult to make specific determinations on the causes for increases and decreases in interaction strength as vehicle attitude and thrust allocation is changed. For a given thrust direction, the maximum thrust firing yields the largest measured interactions, although the interaction for mid and null thrust levels for many allocations are nearly as significant.

\section{ALAS-11 Rev. 3c Configuration}

Figures $25-28$ show ACM pitching moment jet interaction data for the ALAS-11 Rev 3c configuration at subsonic, transonic, and supersonic test conditions. Data at $\mathrm{M}=0.3$ and

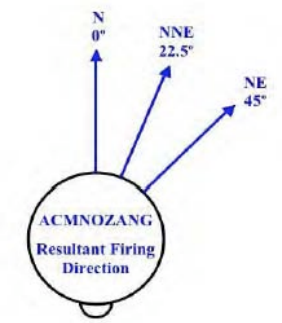

$$
\text { Mach }=0.7, \beta=0
$$

\begin{tabular}{|c|c|}
\hline 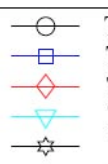 & $\begin{array}{l}\mathrm{TR}=\sim \mathrm{x}^{*} \\
\mathrm{TR}=\sim 3 \mathrm{x} \\
\mathrm{TR}=\sim 5 \mathrm{x} \\
\mathrm{TR}=\sim 6 \mathrm{x} \\
\mathrm{TR}=\sim 10 \mathrm{x}\end{array}$ \\
\hline$* x=$ & rbitrary unit of TR \\
\hline
\end{tabular}
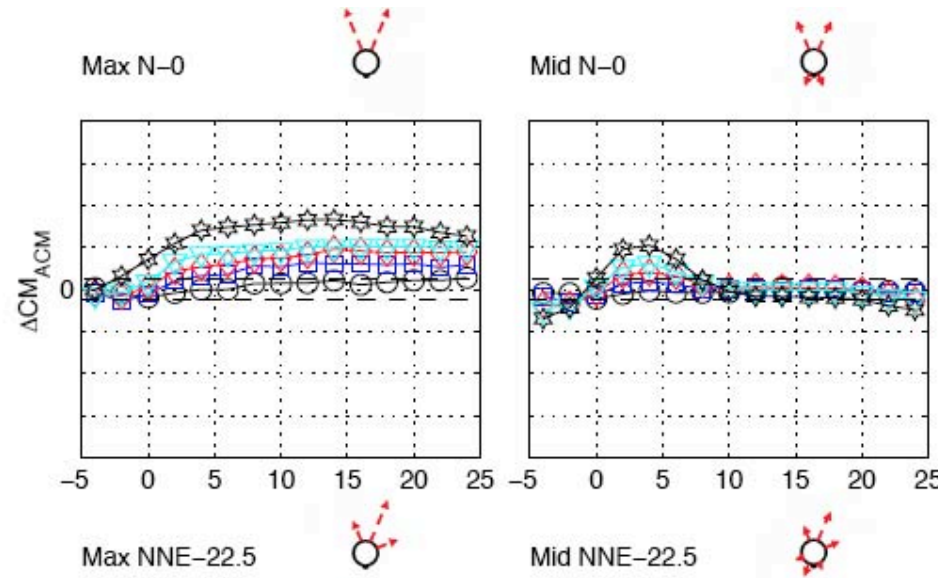

Null N-0 לั
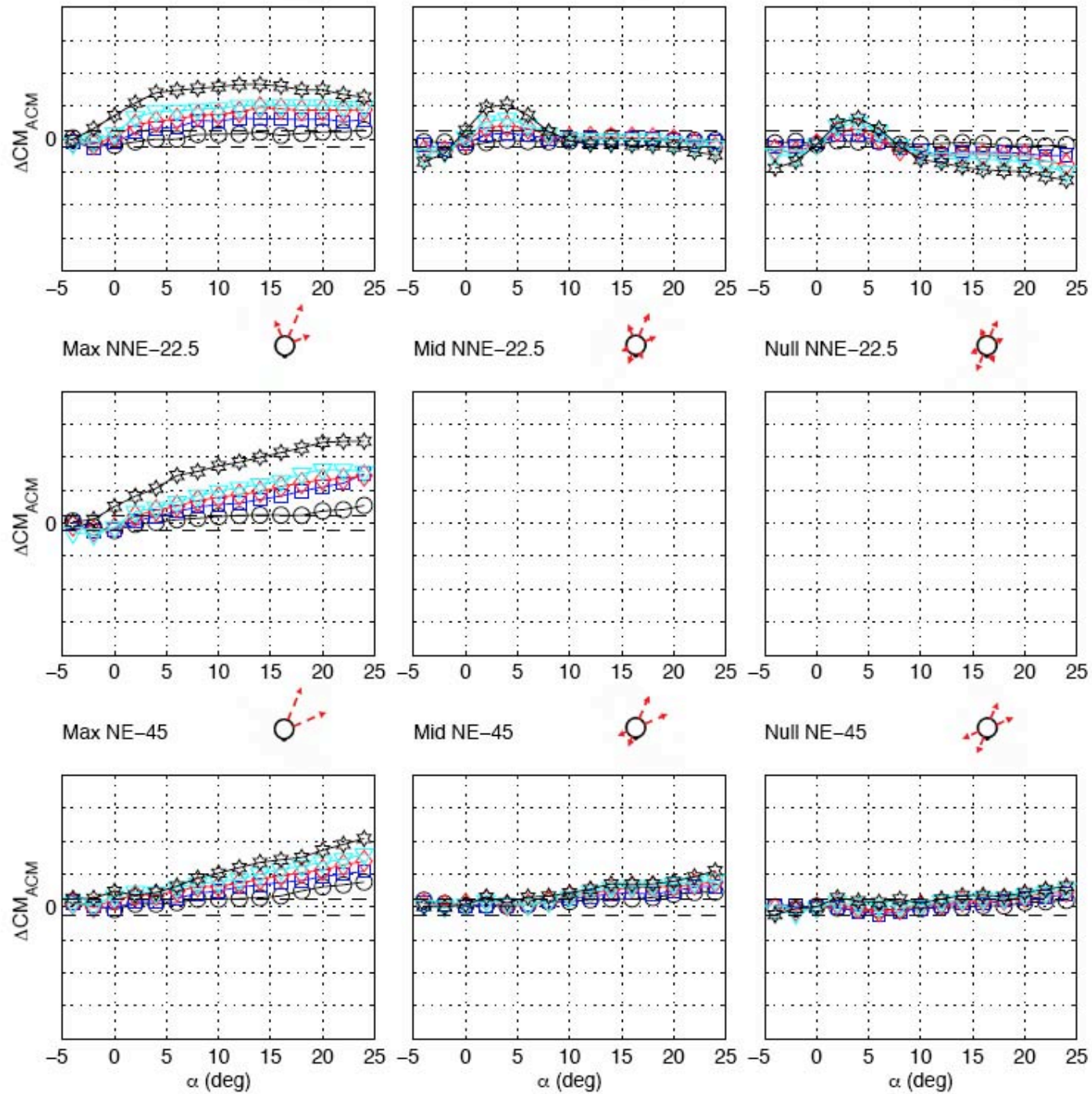

Figure 24(a). Pitching moment coefficient jet interaction data as a function of nondimensional thrust ratio and thrust direction for the LAS-605-068 at M=0.7. 
0.9 were generated in the ARC UPWT 11-FT. Data at $\mathrm{M}=2.5$ were generated in the ARC UPWT 9x7-FT. Data at $\mathrm{M}=4.6$ were generated in the LaRC UPWT Leg II. These data are again presented as a function of model angle of attack for a range of thrust ratios without $\Delta \mathrm{Cm}_{\mathrm{ACM}}$ scales. Note that these ALAS data were obtained over the angle of attack range $-15^{\circ}$ to $+15^{\circ}\left(-16^{\circ}\right.$ to $+16^{\circ}$ for $\left.\mathrm{M}=4.6\right)$. Therefore the 5 azimuth angles shown in Fig. 25-28 were used to populate the entire allocation database every $22.5^{\circ}$ based on both alpha and beta symmetry assumptions. Each figure shows data for max and null thrust allocations for resultant thrust angles of $90^{\circ}, 112.5^{\circ}, 135^{\circ}, 157.5^{\circ}$, and $180^{\circ}$

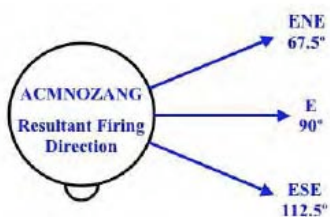

Mach $=0.7, \beta=0$ as indicated by the schematic to the right of the plot key.
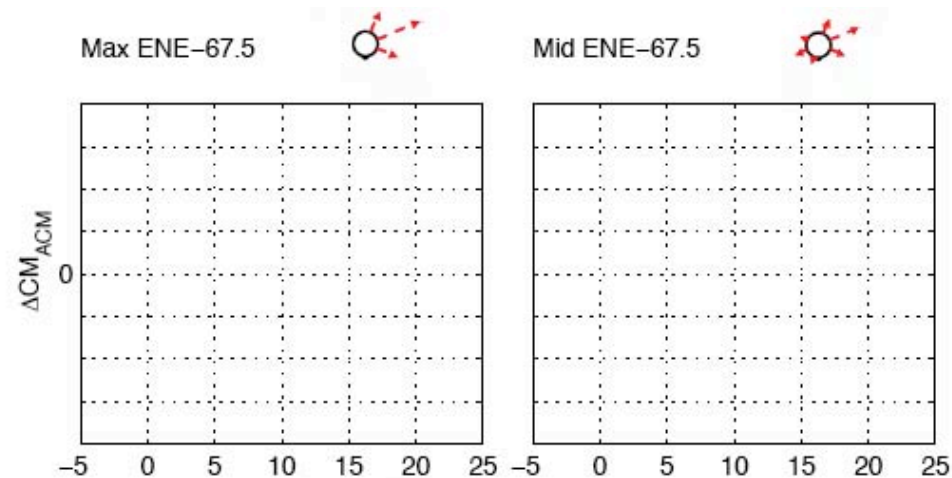

Null ENE-67.5 .ర."
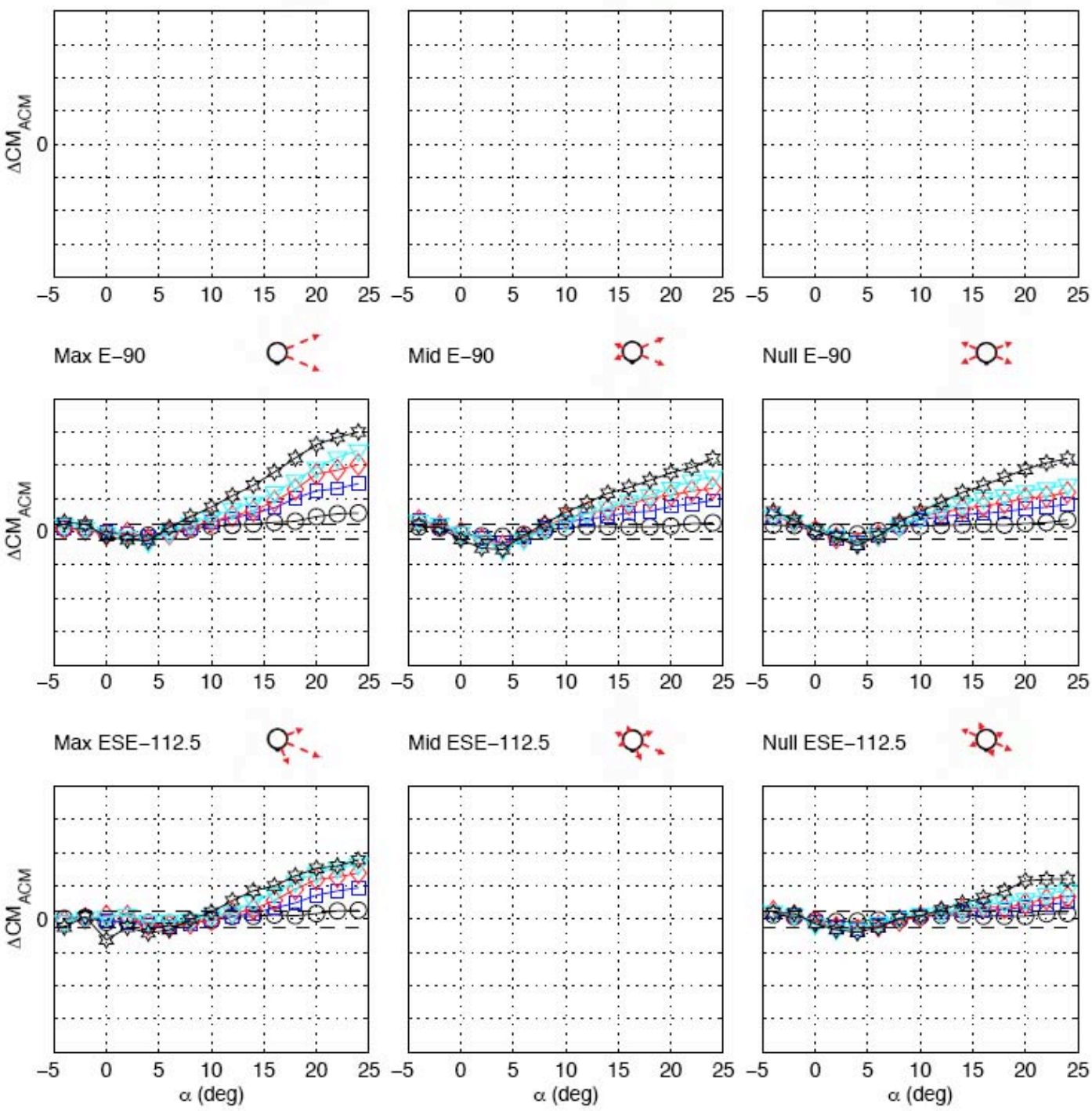

Null E-90 "O"

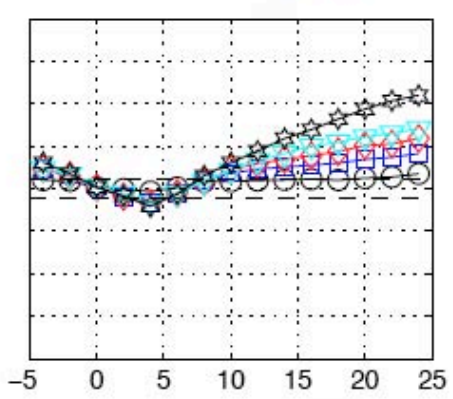

Null ESE-112.5 "Q'

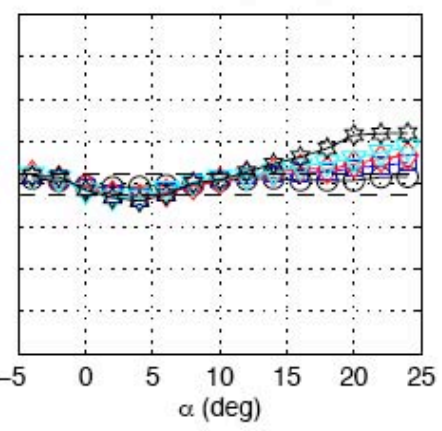

Figure 24(b). Pitching moment coefficient jet interaction data as a function of nondimensional thrust ratio and thrust direction for the LAS-605-068 at M=0.7. 
Again the plots axes for all allocations and all firing directions are shown, with empty plot grids indicating that data were not collected for these test conditions. The small diagrams above each of the nine plot axes show approximate pictorial representations of the firing configuration and orientation for each allocation. One difference from the previous set of plots is that now included with the jet interaction data is the unpowered static aerodynamic data for the ALAS-11 Rev 3c configuration as a point of reference. It is important to note that scales have been adjusted to accommodate both unpowered and powered data and so no magnitude comparisons should be made between these data and the LAS-605-068 plots in Figure 24. Data across the

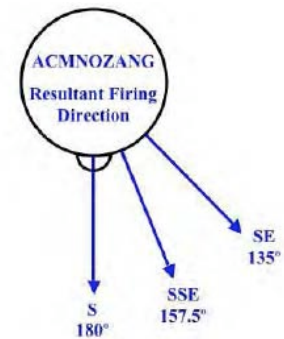
speed regime show varying degrees of non - linearity for all

Mach $=0.7, \beta=0$
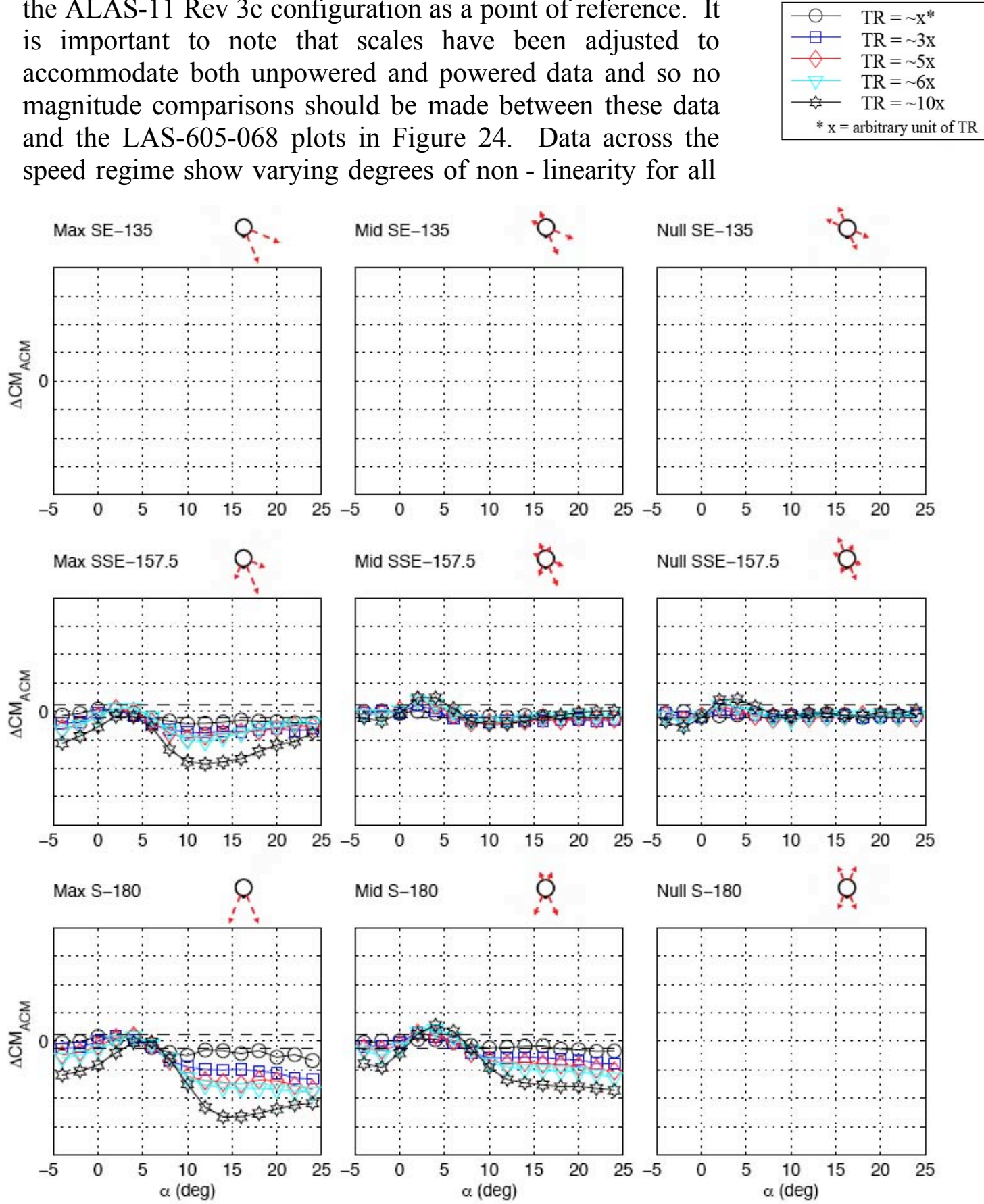

$* \mathrm{x}=$ arbitrary unit of $\mathrm{TR}$
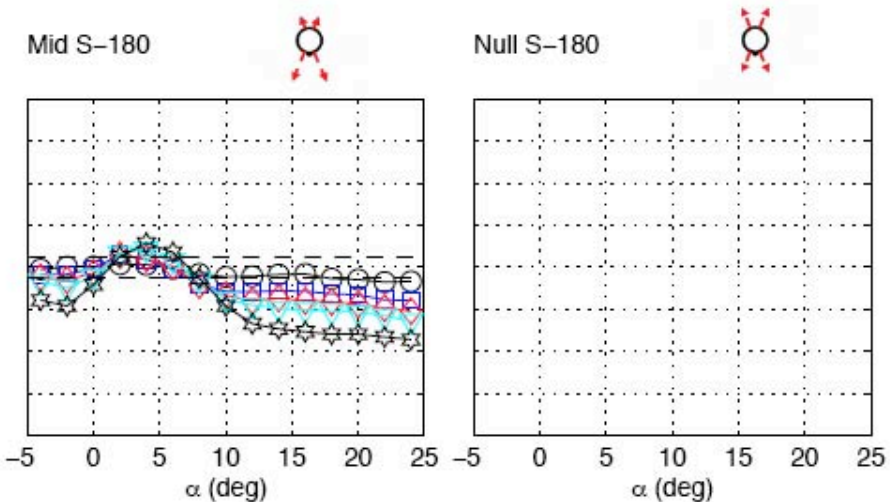

Figure 24(c). Pitching moment coefficient jet interaction data as a function of nondimensional thrust ratio and thrust direction for the LAS-605-068 at M=0.7. 


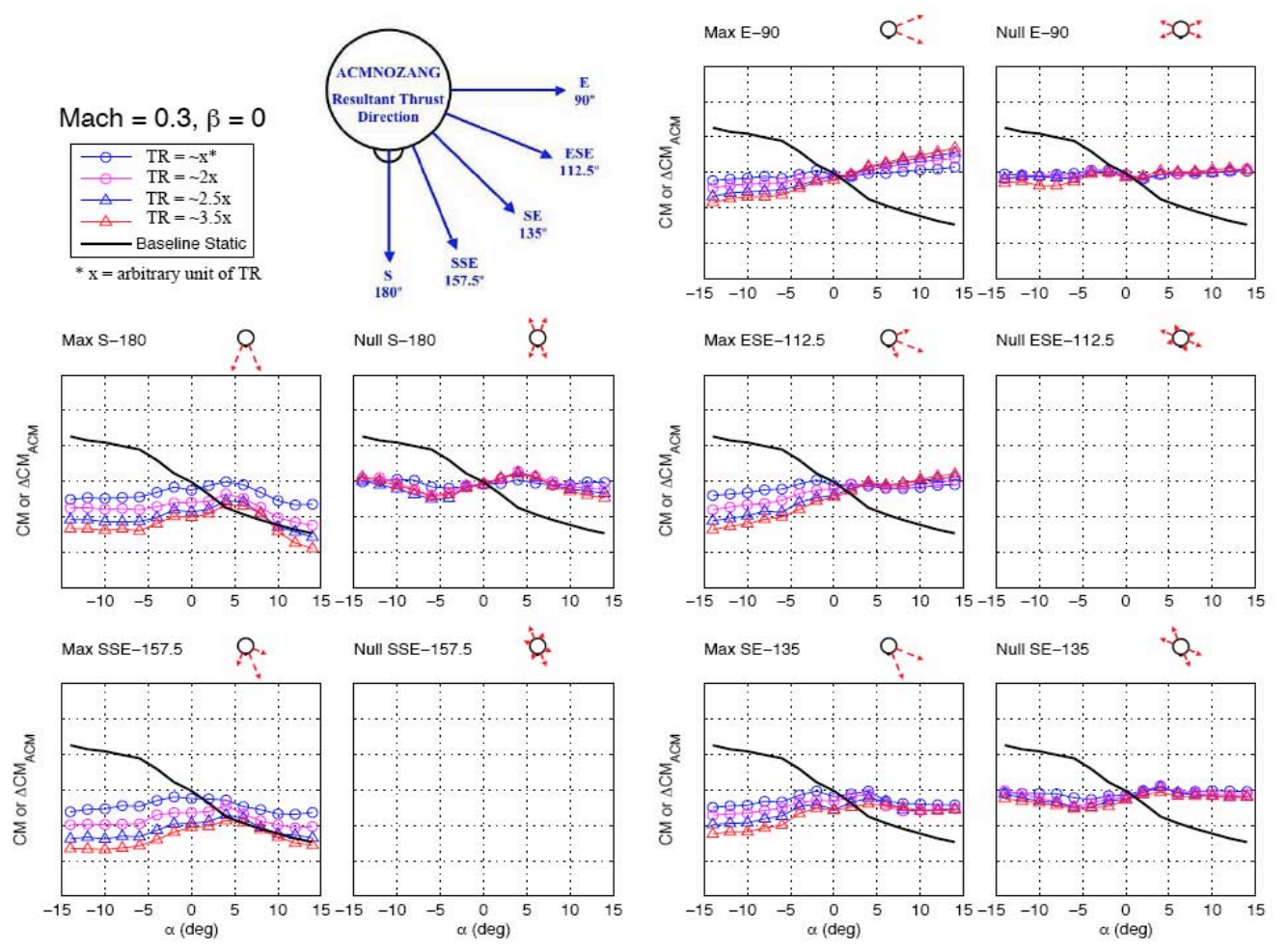

Figure 25. Pitching moment coefficient jet interaction data as a function of nondimensional thrust ratio and thrust direction for the ALAS-11 Rev. 3c at M=0.3.
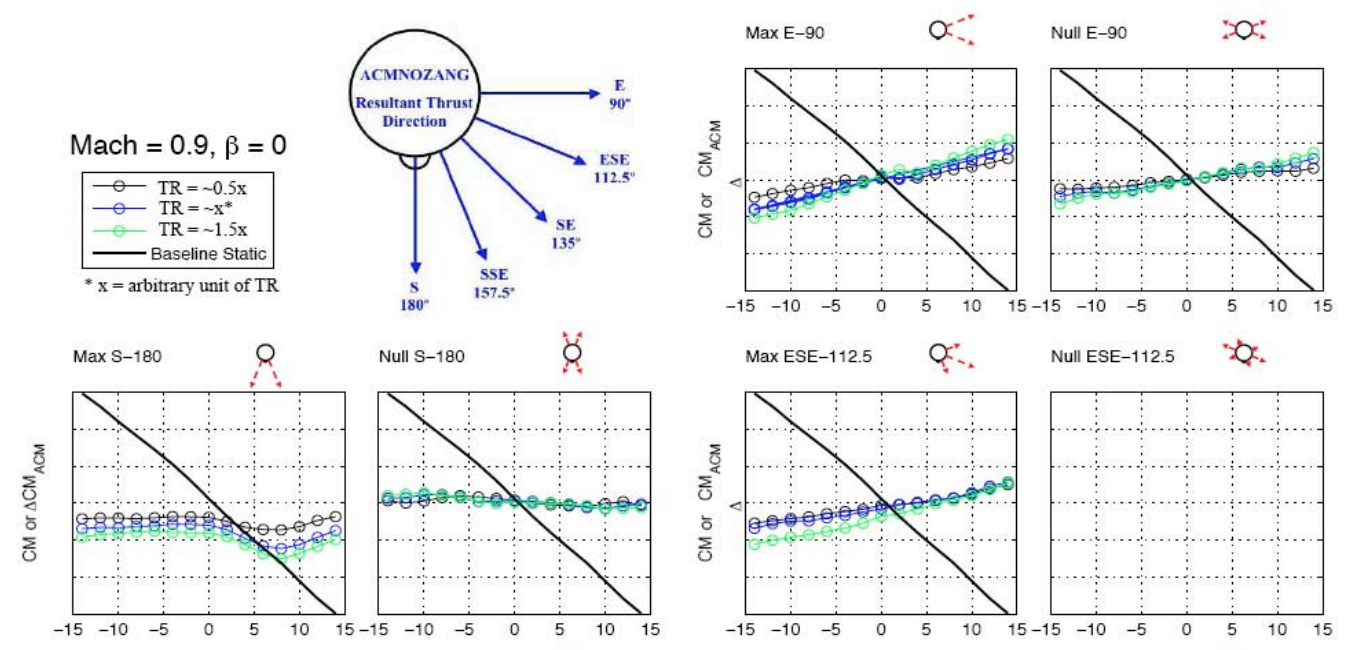

Null ESE-112.5 2.
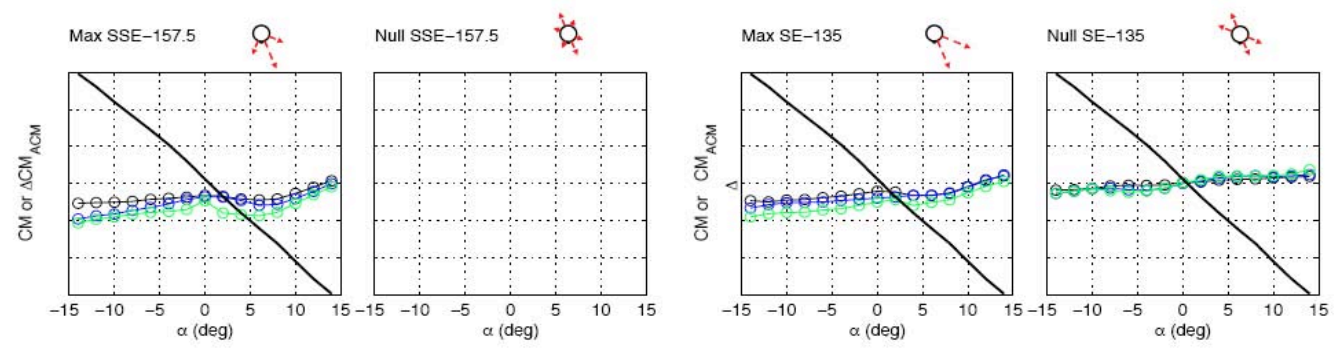

Figure 26. Pitching moment coefficient jet interaction data as a function of nondimensional thrust ratio and thrust direction for the ALAS-11 Rev. 3c at M=0.9. 

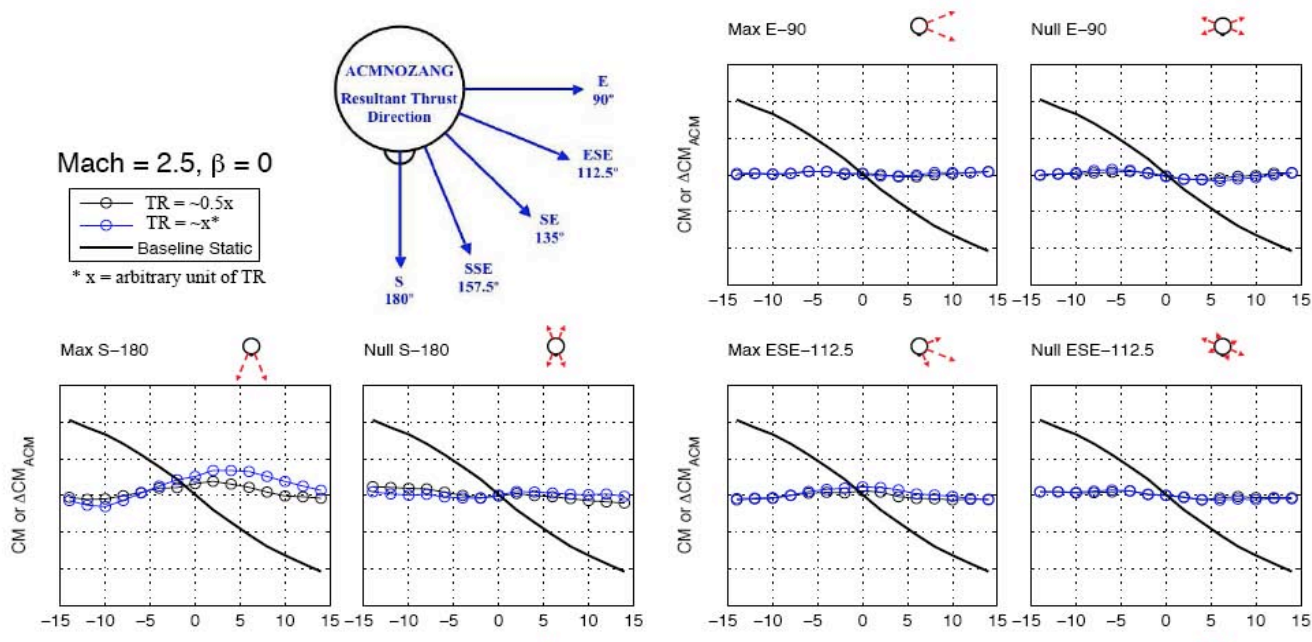

Null ESE-112.5 'Q 'D.
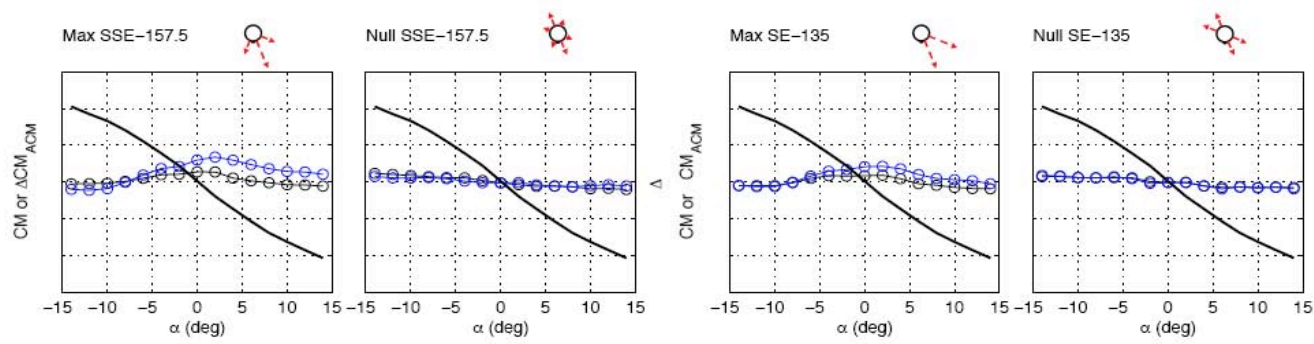

Figure 27. Pitching moment coefficient jet interaction data as a function of nondimensional thrust ratio and thrust direction for the ALAS-11 Rev. 3c at M=2.5.
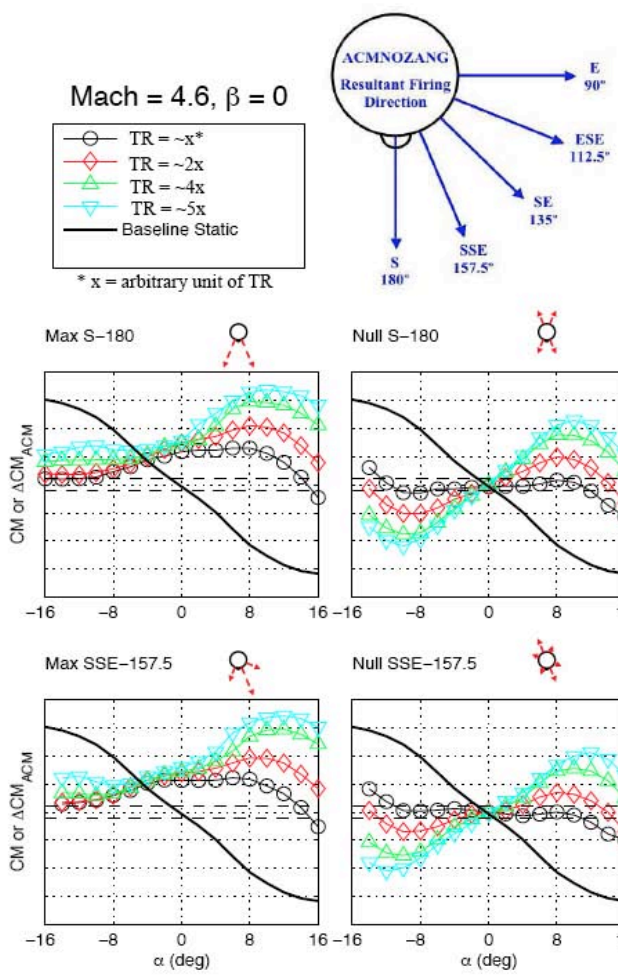
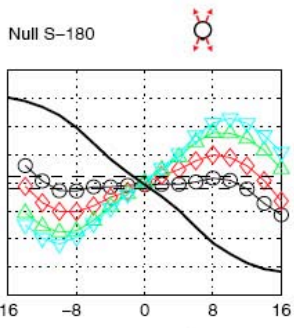

Null SSE-157.5

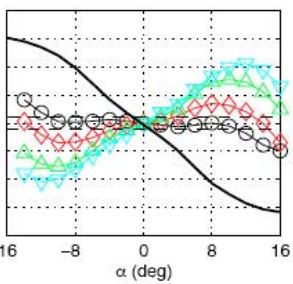

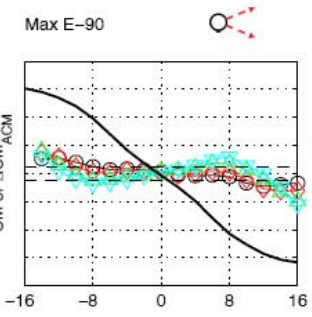

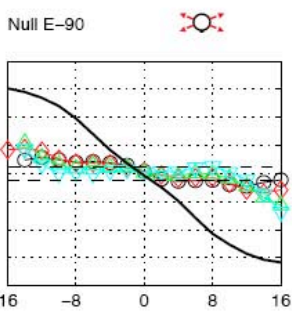

Max ESE-112.5 Q

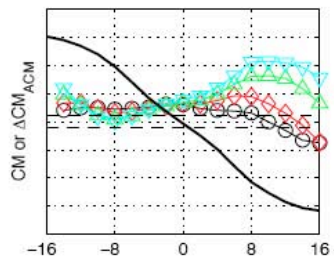

Null ESE-112.5 "Q.

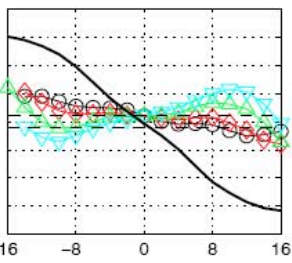

Max SE-135 Q-.

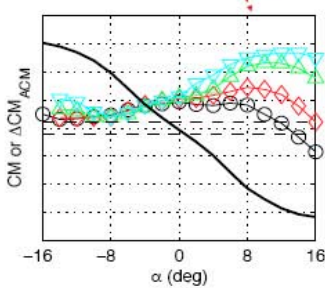

Null SE-135

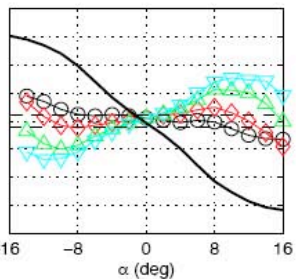

Figure 28. Pitching moment coefficient jet interaction data as a function of nondimensional thrust ratio and thrust direction for the ALAS-11 Rev. 3c at M=4.6. 
allocations. For all azimuth angles and nozzle arrangements, interaction strength increases with increasing thrust ratio and interactions are generally seen to be at a minimum at zero angle of attack. Multiple jet interactions are very complex with both localized and far field disturbance potential and again caution is taken is attempting to understand the behavior of the interaction data. For a given thrust direction, the maximum thrust firing yields the largest measured interactions with null thrust again showing comparable magnitudes. Note that these plots show larger interactions at the low subsonic and high supersonic conditions because a larger range of thrust ratios were tested based on the trajectory simulations in Figure 22.

Facility-to-facility Comparison

Generally the comparison of like data from different facilities provides valuable inputs to overall uncertainty estimation as well as an important basic check of experimental methods and data reduction implementation. Figure 29 shows pitching moment jet increment data at $\mathrm{M}_{\infty}=2.5$ from test 75-AA conducted in the ARC UPWT and test 76-AA conducted in the LaRC UPWT. Data were taken on the same model but with different balances. The very non-linear trends are matched extremely well between the two sets with only small differences in magnitude for some of the thrust allocations.
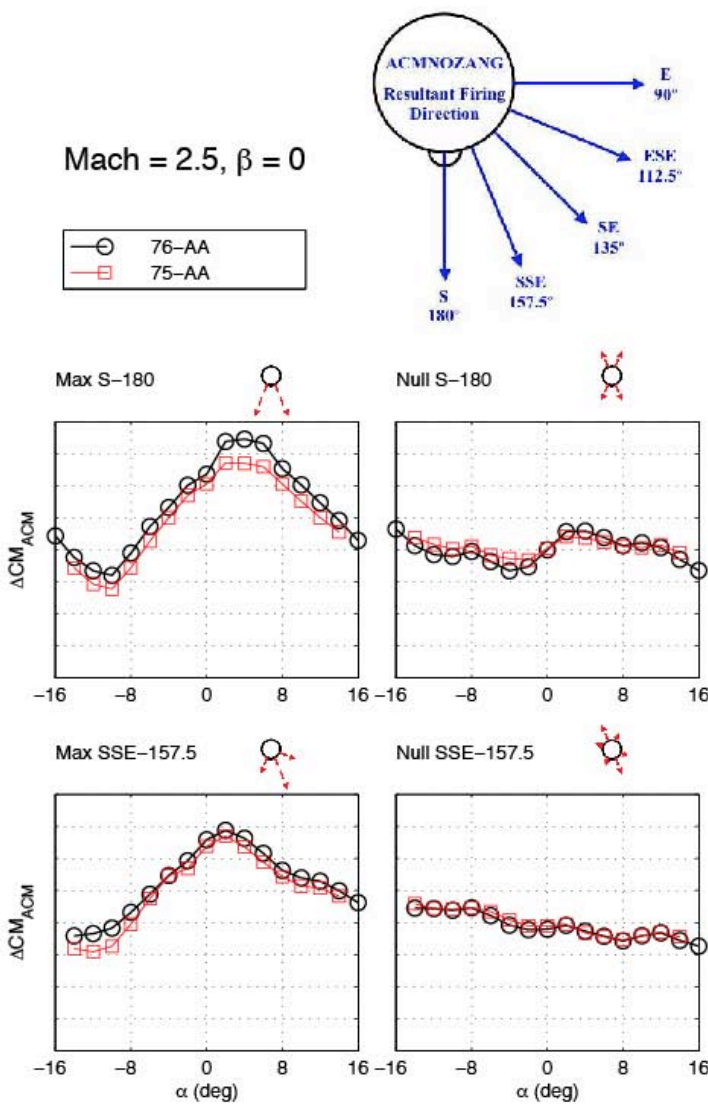

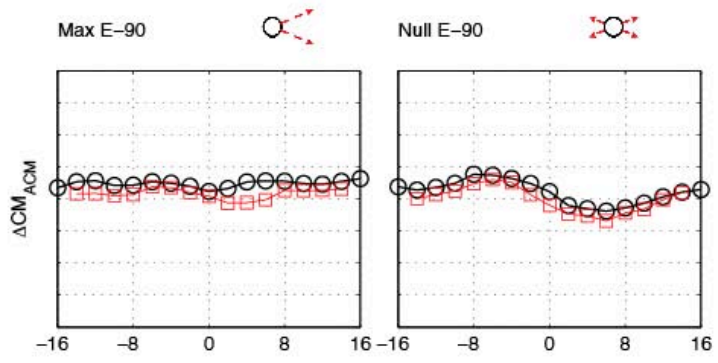

$\operatorname{Max}$ ESE-112.5 Null ESE-112.5 NO'
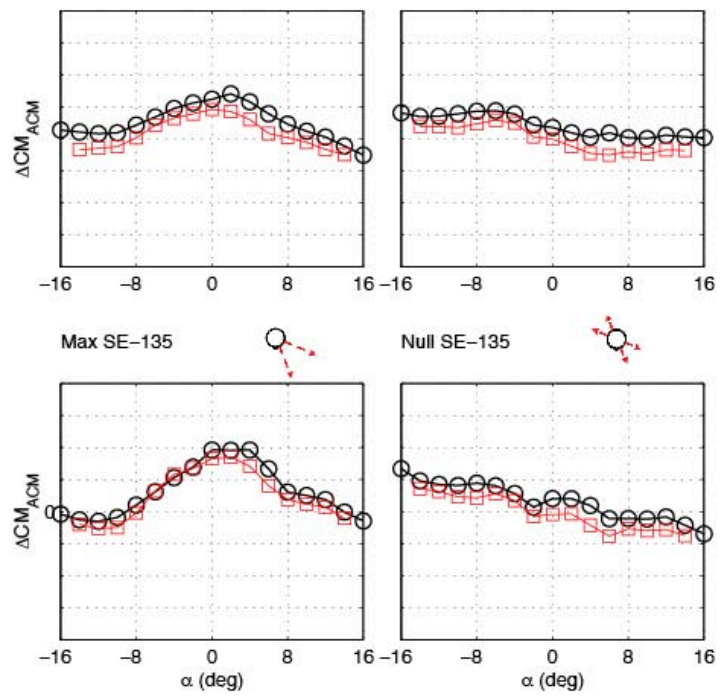

Figure 29. Comparison of pitching moment jet interaction increments at $M_{\infty}=\mathbf{2 . 5}$ from test 75-AA in the ARC UPWT and 76-AA in the LaRC UPWT. 


\section{Lessons Learned}

Each of the three ACM JI test entries provided its own unique challenges, and the planning and execution of these tests over a more than three year period provided the CAP test team with a set of lessons learned that will be very valuable to future powered jet interaction testing programs. Recommendations are highlighted in bold text below.

ACM Modeling

The LAV's eight-nozzle, solid-fueled ACM presented a host of modeling challenges. Model scale dictated that all nozzles had to be fed by a common plenum. Air was the only high-pressure gas readily available in all test facilities. The small scale of the test module resulted in low mass flows that could not be held at a constant elevated temperature. Thus cold gas simulation was the only available option. Lower flow path temperatures imposed a lower nozzle exit Mach number limit to avoid liquifaction within the ACM nozzles, which led to modeling constraints that may have limited the ability to optimize nozzle plume matching. At very low static pressures associated with supersonic test conditions, there was visual evidence (blue coloration) of liquifaction as the plume expanded into the freestream. Uncertainties in the plume physics added to overall uncertainties in plume simulation. Knowledge was gained over the course of the program, using experimental data and computational simulations, which increased confidence in scaling parameters for the ACM nozzles. Larger scale models (necessarily run in larger facilities at much greater test cost) with the ability to run heated flows would allow for a less constrained nozzle design space.

$\underline{\text { Instrumentation }}$

Flow through balances: Temperature monitoring and management is a general issue for all standard strain-gage balances. Temperature effects on balance gages are typically generated via conduction of freestream flow temperatures through the model or the sting, but a flow through balance is also affected by the temperature and pressure of the gas flowing through it. The balance used for the first ACM test entry showed particular sensitivity to temperature and thus a routine of conditioning the balance with external and internal flow for a period of time to allow it to reach typical running temperatures became essential to ensure minimal temperature effects for powered data. Data repeatability showed dramatic improvement with the use of pre-run balance conditioning and thus became standard operating procedure for the remaining entries. Wind-off, jet-on thrust tares presented a temperature problem that could not be addressed with conditioning, as it was a function only of internal flow. Balance temperatures were a strong function of plenum pressure and thus varied significantly through a thrust tare, manifesting in extreme hysteresis of the data (a part of this is traceable to non-dimensionalization of the thrust tare described below). The balance used for supersonic testing in the LaRC UPWT showed much less temperature sensitivity than the balance used for ARC UPWT testing. Resources expended on balance conditioning showed temperature response to be an important criterion in balance selection. The ability to heat the flow and thus maintain a constant temperature throughout a given pressure sweep would be very desirable to minimize thermal effects on the balance data. 
Mass flow meters: Questions still exist regarding mass flow measurements via both the subcritical venturi and coriolis flow meters. Mass flow measurements greater than ideal with deltas increasing with increasing pressures certainly do not negate the possibility of leaks, although none were found for any of the test installations. Recent consultations with coriolis meter users have indicated that factory calibrations may have more temperature sensitivity than cited in accompanying literature. Flow meter accuracy relative to the low mass flows for these test programs may be a factor. With mass flow filtering into so many aspects of data reduction, it is important to have familiarity and a thorough understanding of the chosen mass flow meter and the correlation of its results with measured plenum conditions. Flow meter calibrations should be completed and verified pre-test.

\section{Data Reduction}

Thrust Removal: Initial thrust removal was done as a function of NPR, but reexamined and reformulated due to potentially large extrapolations errors. Upon a more thorough examination of the thrust tare calculations, the additional problem of nondimensionalizing thrust tare data by ideal thrust, $F_{\text {ideal, }}$, was discovered. $F_{\text {ideal }}$ is a function of both measured mass flow, plenum temperature, and NPR and was shown to introduce strong non-linearities to the thrust tare data not observed in the pure balance data. A more through understanding of the thrust equation and the ability to account for ambient pressure differences led to a new thrust removal formation as a function of measured chamber pressure and balance loads, as described in preceding a section. It is important to understand parametric sensitivity to calculated terms in data reduction and potential error resulting from curve-fitting/extrapolation of measured data.

Thrust Ratio Calculation: The inability to measure exact state conditions in the small ACM nozzles made calculation of corresponding nozzle thrust ratio a significant challenge, and one not fully recognized early in the test program. With no dedicated nozzle calibration test facility, single nozzle thrust tares were done in hopes of determining loss factors. All the aforementioned thrust tare data reduction and mass flow measurement issues, in addition to balance accuracy relative to very small thrust loads, contributed to very large uncertainties on single-nozzle data. Computational models of the internal flow path for as-run test conditions proved critical to estimate nozzle losses and to calculate thrust ratio. Flow path calculations done pre-test would provide valuable context for understanding experimental data as it is acquired.

\section{Summary}

A test program to generate ACM jet interaction aerodynamic increment data for two LAV configurations was conducted in the NASA Ames and NASA Langley Unitary Plan Wind Tunnels from August 2007 through December 2009. Using cold air as the simulant gas, powered subscale models were used to generate interference data at subsonic, transonic, and supersonic test conditions for the eight-nozzle, nose-mounted attitude control motor jets. Given the system complexity and the potential for ACM jet plumes to produce highly non-linear control amplifications or attenuations, an extensive jet 
interaction aerodynamic database was required to characterize resulting changes in LAV flight control characteristics. Three complex test programs generated close to 4000 wind tunnel runs over a wide range of flow field and jet simulation parameters for the LAS605-068 and the ALAS-11 Rev. 3c configurations. Nozzle scaling methodologies were developed and refined throughout the course of the test program. Systematic study of measurements taken in earliest test entries, led to significant examination and rework of thrust removal and thrust ratio calculation methods. Data from all test described herein were used as inputs to Orion LAV aerodynamic databases.

\section{References}

${ }^{1}$ McBride, B.J., and Gordon, S., "Computer Program for Calculation of Complex Chemical Equilibrium Compositions and Applications, II. Users Manual and Program Description", NASA RP-1311, June 1996.

${ }^{2}$ Brauckmann, G.J., Greathouse, J.S., and White, M.E., "Rocket Plume Scaling for Orion Wind Tunnel Testing", 29th Applied Aerodynamics Conference, AIAA, Hawaii (submitted for publication).

${ }^{3}$ Amaya, M.A. \& Kmak, A.R. "Capabilities of the NASA Ames Unitary Plan Wind Tunnel (UPWT)", Presented at the $40^{\text {th }}$ Aerospace Sciences Meeting, Reno, Nevada, January $10-15$.

${ }^{4}$ Jackson, C.M.; Corlett, W.A.; Monta, W.J. "Description and Calibration of the Langley Unitary Plan Wind Tunnel,” NASA TP-1905, 1981.

${ }^{5}$ Erickson, G.E.: "Overview of Selected Measurement Techniques for Aerodynamic Testing in the NASA Langley Unitary Plan Wind Tunnel," AIAA 2000-2396, June 2000.

${ }^{6}$ Chan, D.T., Brauckman, G.J., "Flight Reynolds Number Testing of the Orion Launch Abort Vehicle in the NASA Langley National Transonic Facility (Invited)," 29th Applied Aerodynamics Conference, AIAA, Hawaii (submitted for publication).

7Walker, E.L., "Lessons Learned for Orion Aerodynamic Uncertainty Modeling", 29th Applied Aerodynamics Conference, AIAA, Hawaii (submitted for publication).

${ }^{8}$ Bibb, K.L., Robinson, P., Brauckmann, G.J., "Development of the Orion Crew Module Static Aerodynamic Database, Part II: Subsonic" 29th Applied Aerodynamics Conference, AIAA, Hawaii (submitted for publication).

${ }^{9}$ Chan, D.T., et. al., "Modeling Powered Aerodynamics for the Orion Launch Abort Vehicle Aerodynamic Database (Invited)," 29th Applied Aerodynamics Conference, AIAA, Hawaii (submitted for publication.

${ }^{10} \mathrm{http}: / /$ www.anl.gov/TRACC/Computing_Resources/star-ccm.html.

${ }^{11}$ Murphy, K.J., et. al, "Final Report for Test 59-AA: Attitude Control Motor Jet Interaction Testing of LAS-605-068 and Modified ALAS-11 in the Ames Unitary Plan Wind Tunnel." CEV Aerosciences Program, Rept. EG-CAP-10-86, NASA Langley Research Center, July 2011.

${ }^{12}$ Murphy, K.J, et. al, Final Report for Test 75-AA: Attitude Control Motor Jet Interaction Testing of ALAS-11 Rev. 3c in the Ames Unitary Plan Wind Tunnel," CEV Aerosciences Program, Rept. EG-CAP-10-87, NASA Langley Research Center, July 2011.

${ }^{13}$ Paschal, K.B, et. al, "Final Report for Test 76-AA: Attitude Control Motor JetInteraction Testing of the ALAS-11-Rev3c LAV in the Langley Unitary Plan Wind 
Tunnel," CEV Aerosciences Program, Rept. EG-CAP-10-90, NASA Langley Research Center, March 2011. 